\title{
Exploration of energization and radiation in geospace (ERG): challenges, development, and operation of satellite systems
}

\author{
Yosuke Nakamura ${ }^{1 *} \mathbb{D}$, Seisuke Fukuda ${ }^{1}$, Yasuko Shibano ${ }^{1}$, Hiroyuki Ogawa', Shin-ichiro Sakai ${ }^{1}$,

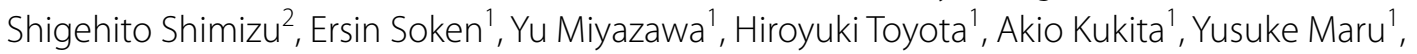 \\ Junichi Nakatsuka', Tomohiko Sakai ${ }^{1}$, Shinsuke Takeuchi ${ }^{1}$, Kenichiro Maki ${ }^{1}$, Makoto Mita', Emiko Ogawa', \\ Yuya Kakehashi ${ }^{1}$, Kumi Nitta ${ }^{1}$, Kazushi Asamura' ${ }^{1}$ Takeshi Takashima ${ }^{1}$ and Iku Shinohara'
}

\begin{abstract}
The exploration of energization and radiation in geospace (ERG) satellite, nicknamed "Arase," is the second satellite in a series of small scientific satellites created by the Institute of Space and Astronautical Science of the Japan Aerospace Exploration Agency. It was launched on December 20, 2016, by the Epsilon launch vehicle. The purpose of the ERG project is to investigate how high-energy (over MeV) electrons in the radiation belts surrounding Earth are generated and lost by monitoring the interactions between plasma waves and electrically charged particles. To measure these physical processes in situ, the ERG satellite traverses the heart of the radiation belts. The orbit of the ERG is highly elliptical and varies due to the perturbation force: the apogee altitude is approximately $32,200-32,300 \mathrm{~km}$, and the perigee altitude is $340-440 \mathrm{~km}$. In this study, we introduce the scientific background for this project and four major challenges that need to be addressed to effectively carry out this scientific mission with a small satellite: (1) dealing with harsh environmental conditions in orbit and electromagnetic compatibility issues, (2) spin attitude stabilization and avoiding excitation of the libration by flexible structures, (3) attaining an appropriate balance between the mission requirements and the limited resources of the small satellite, and (4) the adaptation and use of a flexible standardized bus. In this context, we describe the development process and the flight operations for the satellite, which is currently working as designed and obtaining excellent data in its mission.
\end{abstract}

Keywords: ERG, Arase, Radiation belts, Van Allen belts, Geospace, Small satellite, Project

\section{Introduction}

In the early days of space exploration, the first US satellite, Explorer 1 (launched in 1958), discovered the existence of high-energy charged particles in space within close proximity of the Earth (a region called geospace) using its onboard radiation detector. The observations by subsequent explorers have revealed that high-energy charged particles are distributed in a donut-shaped pattern surrounding Earth (Van Allen and Frank 1959). This

\footnotetext{
*Correspondence: nakamura.yosuke@jaxa.jp

${ }^{1}$ Institute of Space and Astronautical Science, Japan Aerospace Exploration Agency, JAXA, 3-1-1 Yoshinodai, Chuo-ku, Sagamihara, Kanagawa 252-5210, Japan

Full list of author information is available at the end of the article
}

radiative zone is referred to as the "radiation belts" or "Van Allen belts." High-energy charged particles in the radiation belts are trapped in the Earth's magnetic field, and, as a result, electron energies can reach the order of tens of $\mathrm{MeV}$ in geospace. The radiation belts have long been thought to be steady. However, in the 1990s, Combined Release and Radiation Effects Satellite (CRRES), Akebono, and other satellites have shown that the radiation belts change dynamically during space storms in terms of the levels of high-energy electrons (e.g., Ebihara and Miyoshi 2011, and references therein).

The large number of high-energy charged particles in the radiation belts can cause the electronic devices mounted on spacecraft to fail and hamper accurate 
measurements of the charged particles inside the belts. Therefore, it has been difficult to observe and characterize the radiation belts, particularly in the center. Consequently, the questions of when, where, how, and why the high-energy particles in the radiation belts are generated and lost have remained a scientific mystery. Indeed, the physical process of generating relativistic electrons in the radiation belts is still quite controversial. The exploration of energization and radiation in geospace (ERG) satellite launched in 2016 was intended to solve this mystery of the radiation belts.

From an engineering point of view, the scientific measurements were taken using a small 355-kg satellite with as many as nine scientific instruments under the extremely harsh environment in orbit around Earth. The key concepts of the system design include end-to-end systems engineering and comprehensive management of the system parameters, careful consideration of the electromagnetic compatibility (EMC), development of novel attitude sensors and ring-type mission networks, and utilization of a small and flexible standardized scientific satellite bus. The satellite bus system was developed in the SPRINTA mission (Nakaya et al. 2012), so ERG is the second satellite to use this bus but the first to demonstrate its effectiveness.

\section{ERG project}

\section{Project timeline}

The concept of the ERG project was proposed in the early 2000 s by young scientists. After many years of discussion, the Institute of Space and Astronautical Science (ISAS) of the Japan Aerospace Exploration Agency (JAXA) initiated a phase-A conceptual design study in 2010 for the ERG project as the second satellite in a series of small scientific satellites. In 2012, after a system definition review (SDR), the ERG satellite was classified as a formal JAXA project and proceeded to phase $B$, the preliminary design phase; at this time, an ERG project team was organized. A preliminary design review (PDR) was conducted in 2013 and critical design review (CDR) followed in 2014. The ERG satellite, nicknamed "Arase," was finally launched on December 20, 2016, by the Epsilon launch vehicle from Uchinoura Space Center.

\section{Project objectives}

Figure 1 depicts the ERG mission of conducting in situ measurements of the interactions between plasma waves and electrically charged particles. One main purpose of the ERG satellite is to reveal how high-energy electrons are accelerated or created and how space storms develop (Miyoshi et al. 2012, in review). Moreover, because highly

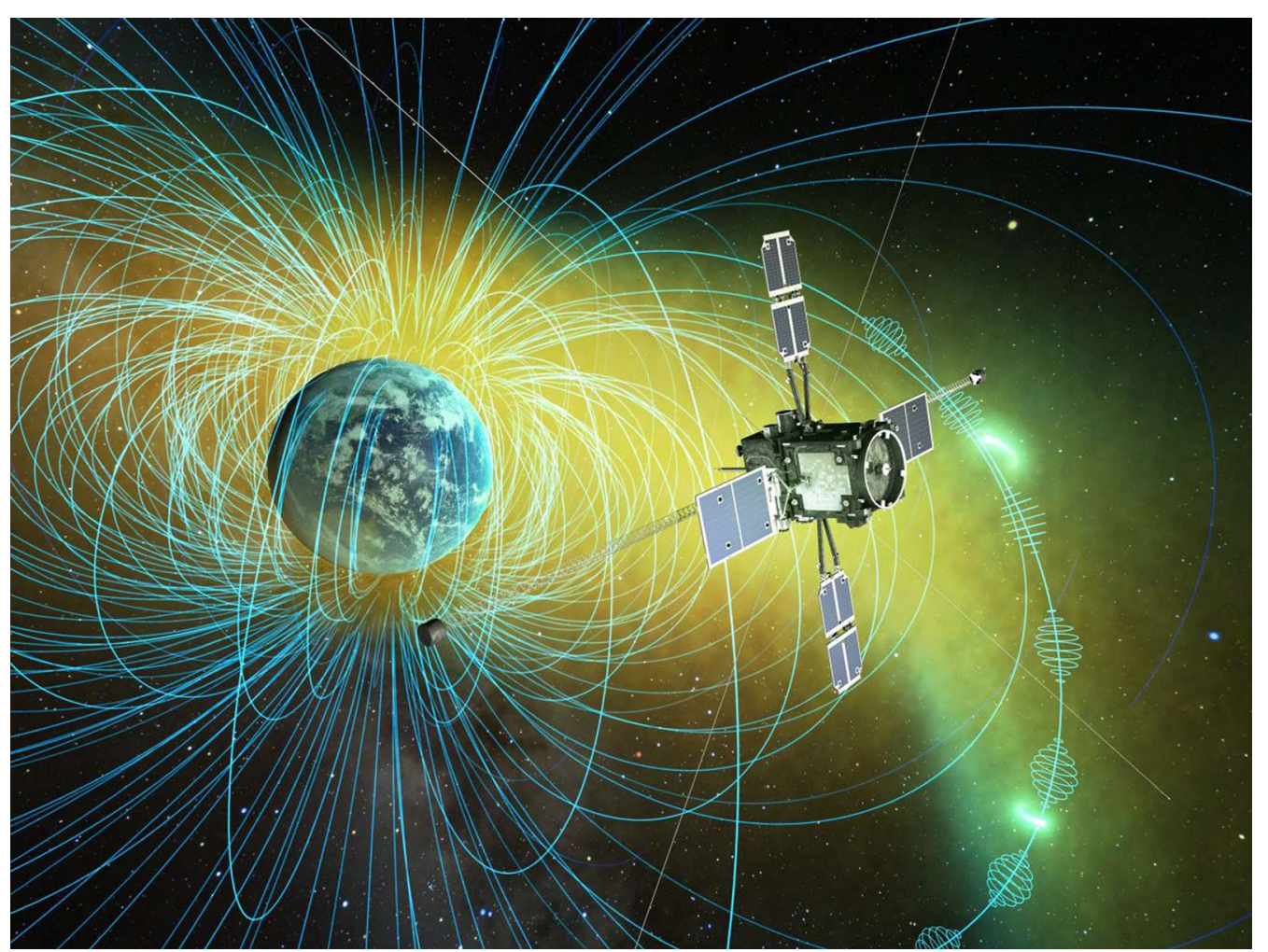

Fig. 1 Image showing the ERG mission, involving in situ measurements of the interactions between plasma waves and electrically charged particles to reveal how these high-energy electrons are accelerated or created in the Van Allen belts and how space storms develop 
energized particles damage equipment by introducing an electrostatic charge and pose a threat of radiation exposure to astronauts, gathering information about space weather forecast on changes in geospace is another important aspect of this project.

Other planets, like Jupiter and Saturn, are also known to have radiation belts. In various parts of the universe, it has been found that electrons are being accelerated close to the speed of light. Thus, the findings of the particle acceleration studies by the ERG satellite can also help unlock the mysteries surrounding the particle acceleration phenomena occurring throughout the universe. Moreover, the development of measurement instruments that can operate in high-radiation environments will be useful for the future exploration of planets with intense radiation belts such as Jupiter.

\section{Integrated studies involving the satellite, ground networks, and simulations}

In order to understand the development of space storms and their effects on the radiation belts, it is necessary to understand the phenomena occurring throughout the geospace region. Detailed observations by the satellite are combined with remote sensing data from ground networks and simulations in an integrated analysis to comprehensively characterize the activity in this region. With this approach, the following teams are also involved in the ERG project: the satellite observation team, the ground-based network observation team, and the integrated data analysis/simulation team. The project science center at Nagoya University and the project science team also work with the project management group.

\section{ERG satellite}

Figure 2 shows the components of the ERG satellite including the bus module and the mission module. The bus module utilizes a small, flexible standardized scientific satellite bus. The satellite deploys four solar-array panels (SAP) upon entering its orbit and deploys four sets of 15-m-long wire probe antennas and two sets of 5-m extendable masts once it is stabilized. The attitude of the satellite is Sun oriented and spin-stabilized around the $+Z$-axis with a nominal spin rate of $7.5 \mathrm{rpm}$ (spin period of $8 \mathrm{~s}$ ).

The designed apogee altitude was approximately $33,100 \pm 2000 \mathrm{~km}$ and was located in the middle of the outer belt; the perigee altitude is greater than $300 \mathrm{~km}$. The actual injected apogee altitude was approximately

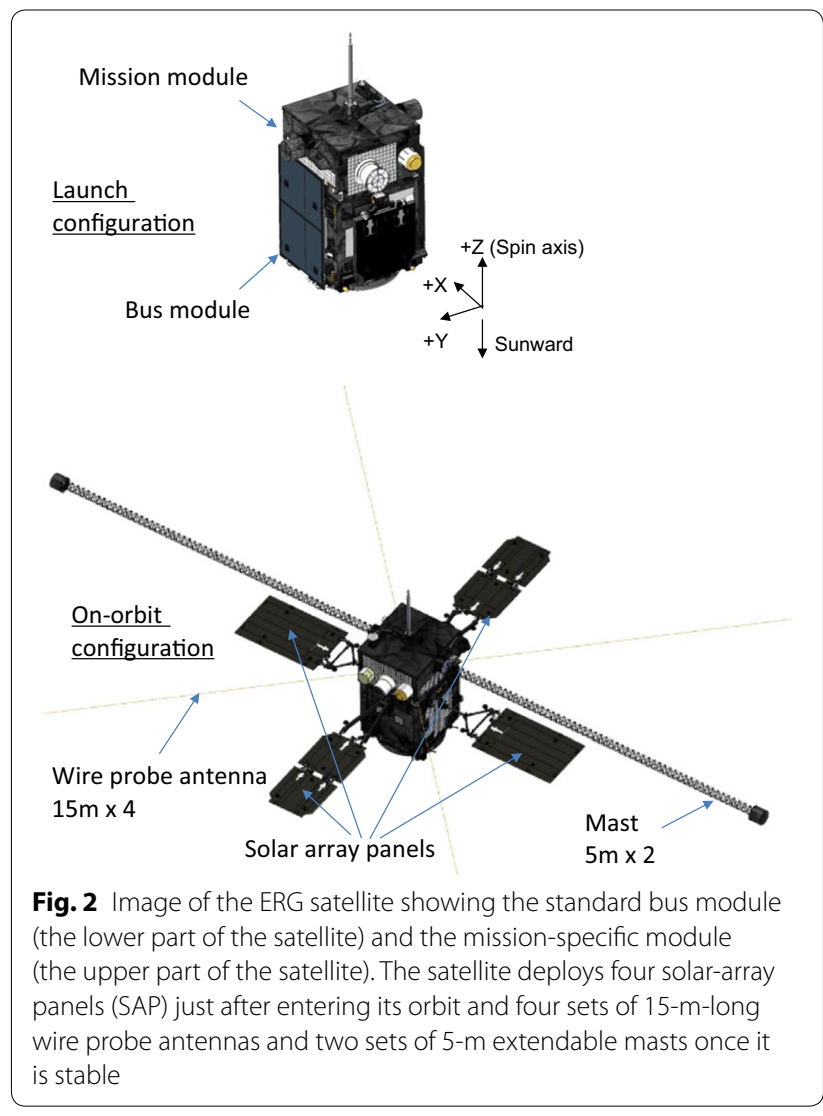

$32,200-32,300 \mathrm{~km}$, and the perigee altitude was approximately $340-440 \mathrm{~km}$ during the first year in orbit as the altitude varies due to the perturbation force. The orbital inclination was approximately $31^{\circ}$, which is almost same as the latitude of the launch site. The satellite does not always travel near the magnetic equatorial plane but has many chances to conduct measurements near the magnetic equatorial plane, including observations of the phase space density, the generation of plasma waves, and accelerations of relativistic electrons.

\section{ERG mission instruments}

Table 1 and Fig. 3 show the mission instruments installed on the ERG satellite. Comprehensive in situ observations of plasma particles (electrons and ions), fields, and waves are important to gather conclusive evidence of waveparticle interactions driving high-energy electron acceleration. Instruments for plasma and particle experiments (PPEs), magnetic field experiments (MGFs), and plasma wave experiments (PWEs) enable these observations. A 
Table 1 Mission instruments

\begin{tabular}{|c|c|c|}
\hline Items & Sensors & Energy range \\
\hline \multicolumn{3}{|l|}{ Plasma and particle experiment (PPE) } \\
\hline \multirow[t]{4}{*}{ Electron } & Low-energy particle experiments_electron analyzer (LEP-e) & $19 \mathrm{eV}-19 \mathrm{keV}$ \\
\hline & Medium-energy particle experiments —electron analyzer (MEP-e) & $10-80 \mathrm{keV}$ \\
\hline & High-energy electron experiments (HEP) & $\begin{array}{l}70 \mathrm{keV}-1 \mathrm{MeV} \\
700 \mathrm{keV}-2 \mathrm{MeV}\end{array}$ \\
\hline & Extremely high-energy electron experiment (XEP) & $400 \mathrm{keV}-20 \mathrm{MeV}$ \\
\hline \multirow[t]{2}{*}{ lon } & Low-energy particle experiments —ion mass analyzer (LEP-i) & $10 \mathrm{eV} / \mathrm{q}-25 \mathrm{keV} / \mathrm{q}$ \\
\hline & Medium-energy particle experiments_-ion mass analyzer (MEP-i) & $10-180 \mathrm{keV} / \mathrm{q}$ \\
\hline \multirow[t]{2}{*}{ Magnetic fields and electromagnetic waves } & Magnetic field experiment (MGF) & - \\
\hline & Plasma wave experiment (PWE) & - \\
\hline Wave-particle interactions & Software-type wave-particle interaction analyzer (S-WPIA) & - \\
\hline
\end{tabular}

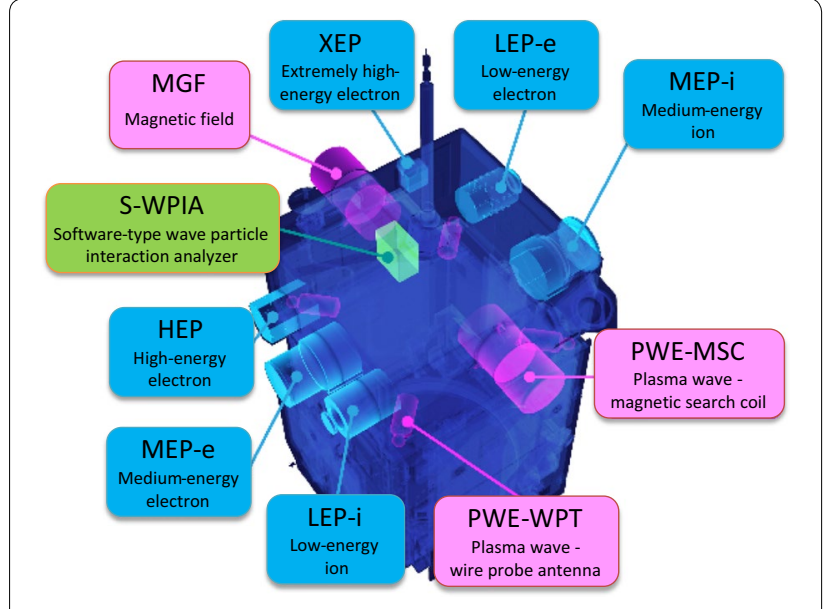

Fig. 3 Arrangement of the scientific measurement instruments

cutting-edge tool for observing wave-particle interactions, called a software-type wave-particle interaction analyzer (S-WPIA), is installed in the mission data processor; this instrument can directly measure the energy exchange between particles and plasma waves.

The PPEs components, such as MEP-e, MEP-I, LEPe, and LEP-i, have fields of view of $180^{\circ}-360^{\circ}$ within the mounting-plane $( \pm X$-plane) direction. Since the ERG satellite is spinning, these sensors have fields of views in the shapes of $4 \pi$-steradian spheres.

\section{ERG satellite system and its subsystems}

Figure 4 shows a block diagram of the system; the bold lines stand for the SpaceWire network. There are three different SpaceWire networks within the ERG satellite system. The first one is for satellite management subsystem (SMS). A satellite management unit (SMU), a data recorder (DR), a telemetry and command interface module (TCIM), an attitude and orbit control processor (AOCP), a power control unit (PCU), heater control electronics (HCE), and mission data processor electronics (MDP-E) are connected through SpaceWire network router (SWR) 1. The second network is for the attitude and orbit control subsystem. Within the network, the AOCP is connected to four attitude control interface modules (ACIMs)-ACSSA, ACMDZ, ACANA, and ACVDI-through SWR 2; each ACIM is connected to AOCS sensors and actuators. The last network is a mission network, in which each mission instrument has a SpaceWire router, which, when thought of as an aggregate system, form a ring-type network.

Table 2 shows the specifications of the satellite. The transponder of the satellite has four different transmission rates, 4, 64 kbps, 0.5 and $1 \mathrm{Mbps}$, for the telemetry downlink. Because the slant range between the satellite and the ground stations varies greatly due to its highly elliptical orbit, one of these four transmission rates is selected to maximize the amount of data transmitted. The reaction control subsystem (RCS) is used to increase the perigee altitude and to control the attitude rate of the satellite. To control the initial spin rate and nutation, quartz rate sensors are used to obtain feedback regarding the satellite attitude rate. The spin axis is estimated on the ground using data from two spin-type sun aspect sensors (SSASs), a geomagnetic aspect sensor (GAS), and a small star scanner (SSC). 


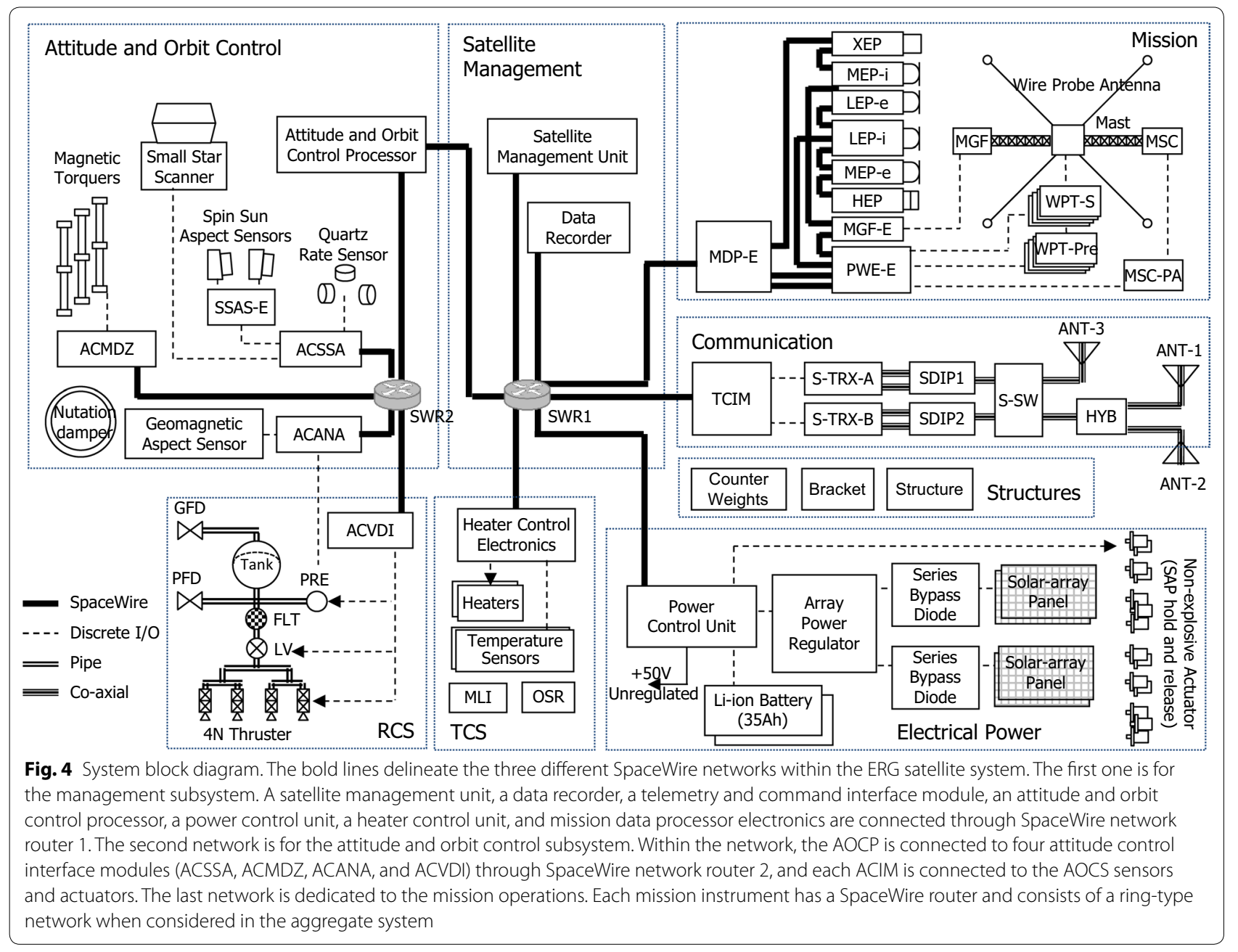

Table 2 System specifications

\begin{tabular}{ll}
\hline Items & Specifications \\
\hline S/C bus & Small, flexible standardized scientific satellite bus \\
Mass & Approx. $355 \mathrm{~kg}$ (wet) \\
& Bus module: $244 \mathrm{~kg}($ wet) $/ 219 \mathrm{~kg}$ (dry) \\
& Mission module: $111 \mathrm{~kg}$ \\
Power & More than $700 \mathrm{~W}$ with four solar-array panels \\
& 35 Ah lithium-ion battery \\
Size & Launch configuration: $1.5 \times 1.5 \times \mathrm{H} 2.7 \mathrm{~m}$ \\
& After deployment: $31.2 \times 31.3 \times \mathrm{H} 2.7 \mathrm{~m}$ \\
Attitude & Spin-stabilized \\
& Accuracy of the determination of the spin axis: less \\
& than $0.5^{\circ}$ with the SSC \\
Communication & S-band \\
& $4 \mathrm{k} / 64 \mathrm{k} / 0.5 \mathrm{M} / 1 \mathrm{Mbps}$ (downlink) \\
& $4 \mathrm{k} / 256 \mathrm{kbps}$ (uplink) \\
Orbit & Highly elliptical orbit that varies due to the perturba- \\
& tion force \\
& Altitude of perigee: approximately $340-440 \mathrm{~km}$ \\
& Altitude of apogee: approximately $32,200-32,300 \mathrm{~km}$ \\
& Inclination: approximately $31^{\circ}$
\end{tabular}

The mission module is mounted on the bus module. Its thermal and structural design is independent of the bus system, and its interface is defined cleanly, which is a fundamental feature of the standard bus. Two sets of mission data processors and recorders (mission data processors (MDP) and MDRs) are installed in the MDP-E and behave as gateways to the satellite management network.

\section{Challenges in the design of the ERG system} Environmental conditions in orbit and EMC considerations Table 3 summarizes the challenges associated with the harsh environmental conditions and the EMC requirements and the steps taken to address these issues.

The satellite must tolerate harsh environmental conditions. High-energy electrons in the outer radiation belt around the apogee can cause electric charges and discharges, and the charged particles can cause failures in electronic devices. For example, the total ionized dose per year is estimated to be around $7.8 \times 10^{5}$ gray for the outer mounted components and $1.0-2.2 \times 10^{3}$ gray for 
Table 3 Summary of the challenges associated with the extremely severe environmental conditions in orbit and the EMC requirements and the steps taken to address them

\begin{tabular}{ll}
\hline Challenges & Solutions \\
\hline RE02 & $\begin{array}{c}\text { Comprehensive management of the EMC from } \\
\text { the component level to the system level, } \\
\text { including design, testing, and adjustment }\end{array}$ \\
$\begin{array}{c}\text { Static charge (surface } \\
\text { conductivity) }\end{array}$ & $\begin{array}{c}\text { Careful selection of the surface material after } \\
\text { thorough radiation and AO flux tests }\end{array}$ \\
Radiation effects & $\begin{array}{c}\text { Optimize the arrangement and thickness of the } \\
\text { radiation shielding for the electric components } \\
\text { and the use of SOl processors }\end{array}$ \\
\hline
\end{tabular}

the inner mounted components. A large flux of atomic oxygen (AO) around the perigee, which is estimated to be $3.9 \times 10^{23}$ atoms $/ \mathrm{m}^{2}$ per year, will cause the surface materials of the satellite to degrade.

To accurately collect scientific data about the electrically charged particles, magnetic field, and electromagnetic waves, it is necessary to prevent the formation of a static charge on the satellite surface; moreover, to reduce the noise in the recorded data, it is important that the system meets strict EMC requirements in terms of the radiated electric field noise (RE02) and radiated magnetic field noise (RE04). Figure 5 shows an image of an EMC test conducted on the system, and Figs. 6 and 7 show the RE02 and RE04 results from the test. The RE02 results almost satisfied the requirements for the ERGs. About

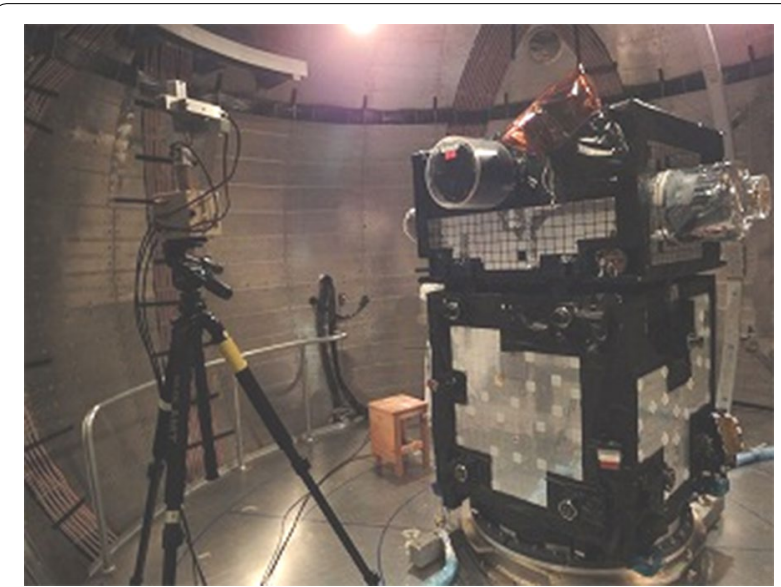

Fig. 5 System electromagnetic compatibility (EMC) test conducted, while the whole satellite system is inside a magnetic-shielded room

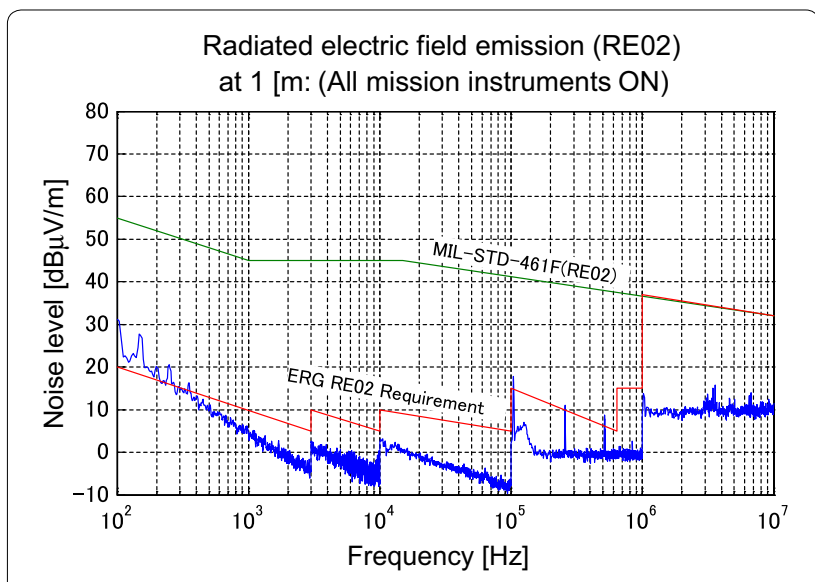

Fig. 6 Radiated electric field noise (RE02) measured in the system electromagnetic compatibility (EMC) test

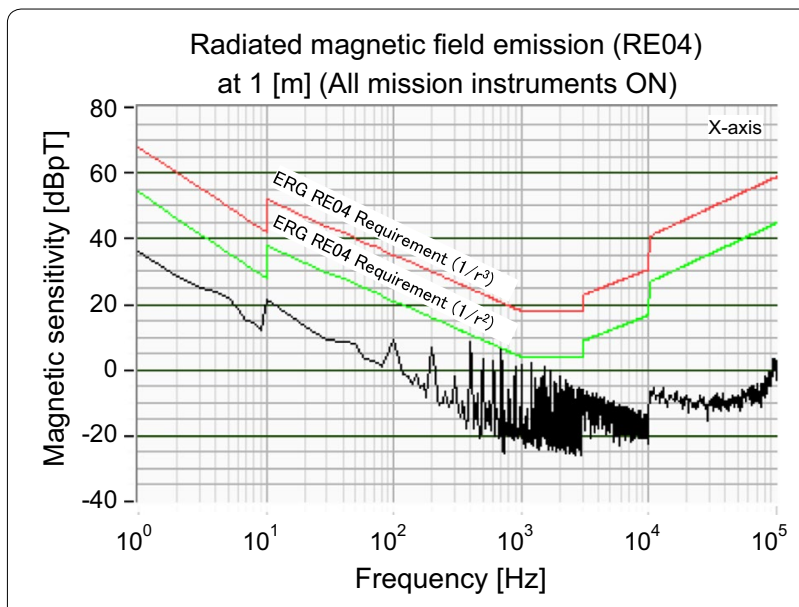

Fig. 7 Radiated magnetic field noise (RE04) measured in the system electromagnetic compatibility (EMC) test. There are two levels of requirements for each instrument: The emission level must be attenuated in proportion to the square or the cube of the distance. The emission level approaches the cube of distance if the emission source is point-like and becomes close to the square of distance if not

EMC requirements from the scientific requirements, please see Kasahara et al. (2018a).

To achieve radiation and $\mathrm{AO}$ tolerance while maintaining the surface conductivity of the satellite, a black polyimide film is used as a surface material for multilayer insulation, and other thermal control materials were carefully selected based on thorough radiation and AO flux tests (Shibano et al. 2015). The EMC level was 
comprehensively managed, from the electrical parts and components to the satellite system. For example, double shields were applied to the harnesses, and EMC filters were added to the PCU. To protect the electrical components from radiation, the arrangement and thickness of the radiation shield were optimized, and a silicon-oninsulator (SOI) structure was adopted for the processors to prevent single-event latch-up. These countermeasures against the severe environmental conditions are currently working well in orbit. For example, no uncorrectable 2 bit errors of the onboard memories have occurred over a year in space, and no degradation in the mission data has been observed so far.

\section{Spin attitude stabilization and minimizing the libration of the flexible structures}

Table 4 summarizes the challenges associated with the spin attitude stability and the libration of the flexible structures, as well as the steps taken to address these issues.

Table 4 Summary of the challenges associated with the spin attitude stabilization and flexible structures and the steps taken to address them

\begin{tabular}{ll}
\hline Challenges & Solutions \\
\hline $\begin{array}{l}\text { Spin instability in the initial } \\
\text { configuration }\end{array}$ & $\begin{array}{c}\text { Active nutation control using RCS } \\
\begin{array}{l}\text { Nutation angle (tilt angle) } \\
\text { Spin stability (momentum- } \\
\text { of-inertia ratio) }\end{array}\end{array}$ \\
$\begin{array}{c}\text { Comprehensive management of the mass } \\
\text { properties from the component level to } \\
\text { the system level, including the design, } \\
\text { wire antenna } \\
\text { testing, and adjustment }\end{array}$ \\
$\begin{array}{c}\text { Moderate MTQ control and demagnetiza- } \\
\text { tion } \\
\text { Libration tests of a wire probe antenna on } \\
\text { the ground }\end{array}$ \\
$\begin{array}{c}\text { Newly developed spin-type star scanner } \\
\text { axis }\end{array}$
\end{tabular}

The ERG is a spin-stabilized satellite. To minimize its nutation motion, the mass properties of the satellite are comprehensively managed from the component level to the system level. In the launch configuration, the SAPs, masts, and wire probe antennas are stowed so the maximum moment of the inertia axis is not aligned to the spin axis, and therefore, the satellite is geometrically spin unstable. To compensate for this instability, active nutation control is conducted using thrusters.

After the SAPs, masts, and wire probe antennas are deployed, coupling motion occurs between the nutation of the satellite body and the libration of the wire probe antennas, particularly when the thrusters are used to control the satellite's attitude. The Sun direction moves approximately $1^{\circ}$ per day due to the revolution of Earth around the Sun. Thus, the spin axis must be controlled to track the Sun. During the science operation phase, magnetic torquers (MTQs) are used instead of the RCS for the spin axis control operation in order to avoid exciting the libration in the flexible structures such as the wire probe antennas and extendable masts. Libration tests of a wire probe antenna were conducted on the ground to determine its damping coefficient; the libration angle of the wire probe antennas was estimated to be in the range of $0.004^{\circ}-0.204^{\circ}$ based on a coupling motion analysis of the satellite body and the antennas. Figure 8 shows images of the system mass property test. To minimize the tilt angle (the angle between the principal spin axis and the system $Z$-axis), the system mass properties were measured along each axis and adjusted precisely. Since tilt angle must be less than $0.5^{\circ}$, it was adjusted to be less than $0.15^{\circ}$.

Furthermore, because the satellite's orbit is highly elliptical, the MTQ control is effective only when its altitude less than $4000 \mathrm{~km}$, where Earth's magnetic field is strong. Further, because operating the MTQs induces magnetic noise to the scientific instruments, the drive duration
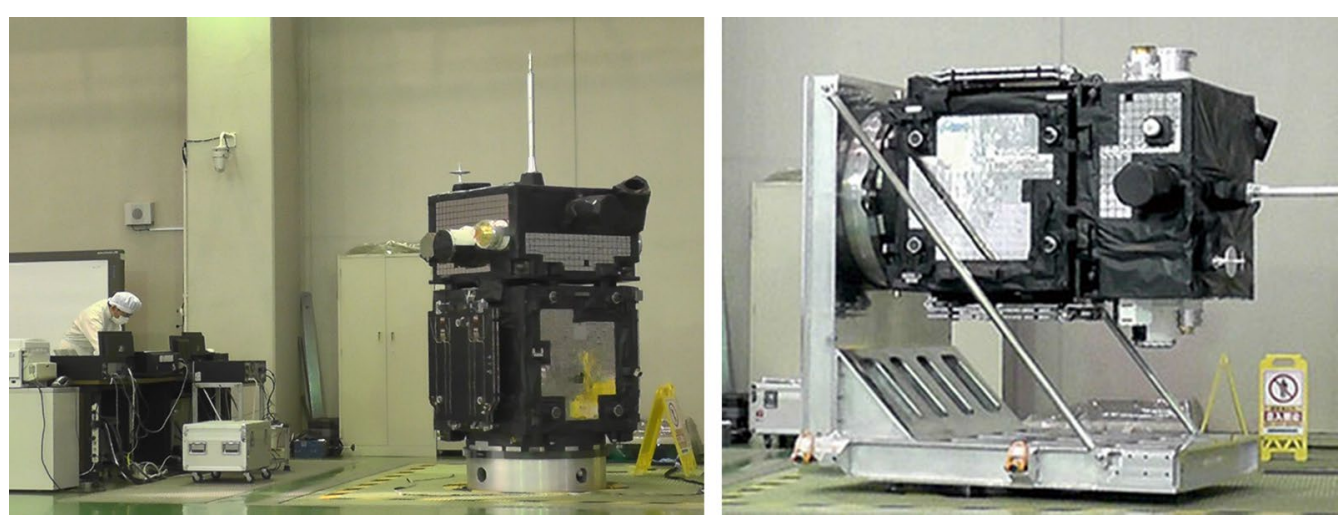

Fig. 8 Test of the mass properties of the system 
Table 5 Spin axis determination results and accuracy of the small star scanner (SSC)

\begin{tabular}{lcccc}
\hline & Alpha Aur and Alpha Orionis & Beta Taurus and Alpha Orionis & Beta Taurus and Alpha Aur & Accuracy (max-min) \\
\hline Declination & $23.86^{\circ}$ & $23.75^{\circ}$ & $24.05^{\circ}$ & $0.30^{\circ}$ \\
Right ascension & $117.40^{\circ}$ & $117.50^{\circ}$ & $117.50^{\circ}$ & $0.10^{\circ}$ \\
\hline
\end{tabular}

must be minimized and a demagnetization operation is required after the use of MTQs.

The attitude of the satellite is estimated, and the spin axis and the spin rate control commands are planned from the ground. The ERG satellite has two SSASs, a GAS, and newly developed spin-type star scanner for determining the attitude offline (Soken et al. 2017). The accuracy of determining the spin axis vector is an important science requirement for the ERG, since Van Allen Probes did not have accurate spin axis determination method and plagued by the nutation. Using the SSC mounted on the ERG, the accuracy at a spin rate of $7.5 \mathrm{rpm}$ was within $0.5^{\circ}$ based on the specifications. Table 5 shows the results of a test of the accuracy of the spin axis determination using the SSC conducted on January 21, 2017. By exchanging the first and second vectors in the TRIAD method, the accuracy of the spin axis determination can be estimated within $0.5^{\circ}$. The accuracy of determining the spin axis vector using the SSAS and the GAS at the perigee was within $5.0^{\circ}$ based on the design specifications and within $1.0^{\circ}$ compared with the results of the SSC-based in-orbit estimation.

\section{Appropriate balance between mission requirements and limited resources of a small satellite}

Table 6 summarizes the challenges of creating an appropriate balance between the mission requirements and limited resources of the small satellite used in this project as well as the strategies used to address these issues.
The ERG satellite is a small satellite with nine scientific instruments; its power, weight, and data downlink rate are limited. The power and weight of the satellite are comprehensively managed from the component level to the system level. Single nonredundant components were used to reduce the number of components, and systemlevel functional redundancies were applied. Figure 9 shows the details of the SpaceWire ring-type network used for the mission. In the network, each instrument has a CPU board that has functionalities as a SpaceWire router and a data processor. Part of the mission data is compressed within each instrument to reduce the size of the downlink data. This architecture enables high-speed data sharing between the mission components to facilitate the integrated data analysis by the S-WPIA installed in MDPs and MDRs. In the ring-type network, there are four spoke routes connecting the MDPs and MDRs to the instruments' CPUs alternately for system-level redundancy. Thus, if an instrument fails, the data network routing can be reconstructed to disconnect only the failed instrument and connect neighboring CPUs to the corresponding MDP or MDR (Takashima et al. 2018).

Achieving a certain level of quality with a limited schedule while minimizing the cost was another challenge in the ERG project. The use of the flexible standardized bus for the series of small scientific satellites significantly contributed to the ability to work around these challenges.

Table 6 Summary of the challenges associated with attaining an appropriate balance between the mission requirements and the limited resources of the small satellite and the steps taken to address them

\begin{tabular}{|c|c|}
\hline Challenges & Solutions \\
\hline \multirow[t]{2}{*}{ Power requirements and weight } & Comprehensive management from the component level to the system level \\
\hline & Single nonredundant components \\
\hline High-speed data sharing for S-WPIA & SpaceWire ring-type network \\
\hline Amount of data & Intelligent mission processors to compress the mission data from each instrument \\
\hline Quality versus limited schedule and cost & Flexible standardized bus \\
\hline Amount of mission data obtained in the operation & Optimized operation based on the graph-theoretic approach \\
\hline
\end{tabular}




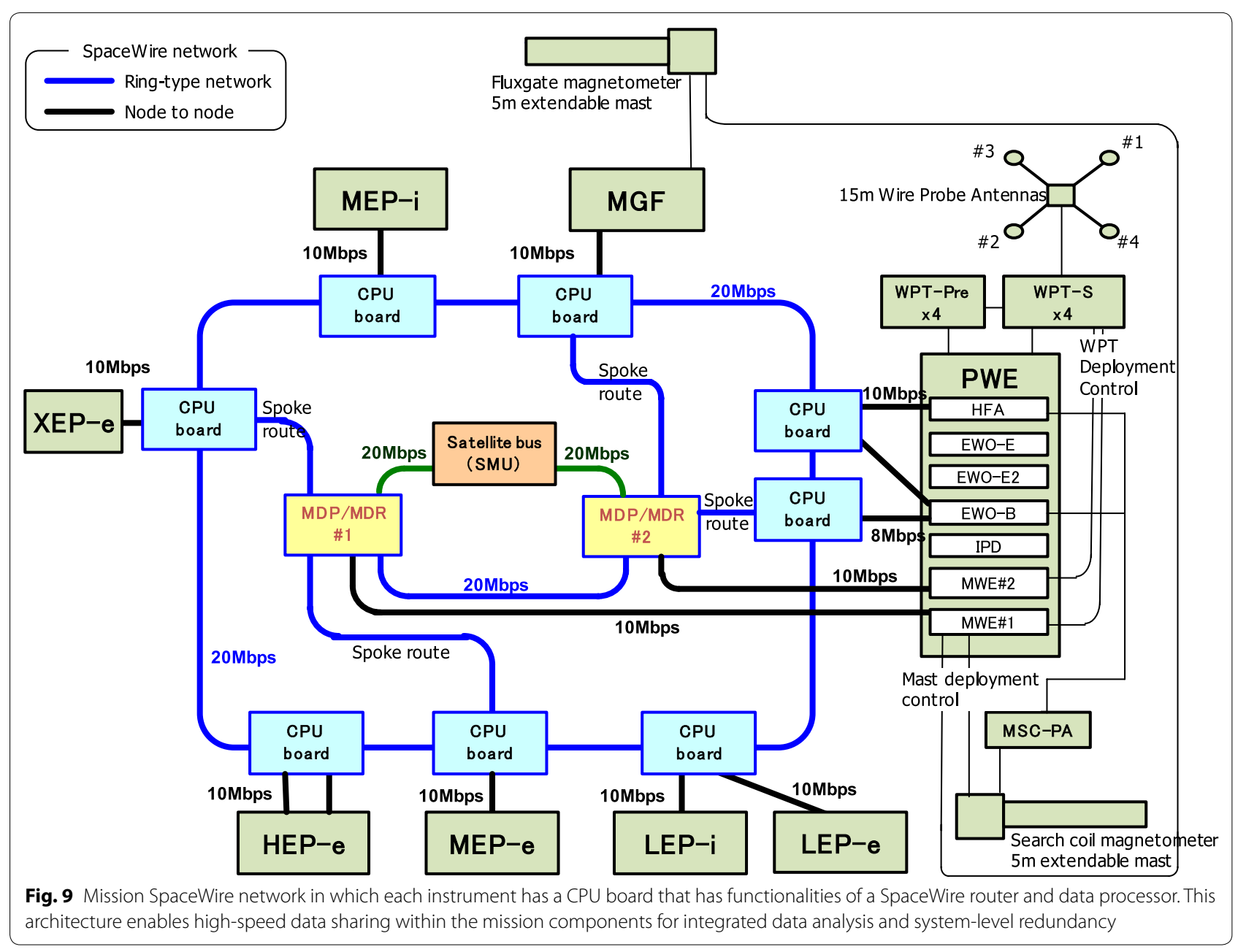

In the operation phase, we tried to maximize the amount of downloaded data. Since the satellite's orbit is highly elliptical, the distance between the satellite and the ground stations fluctuates significantly, and therefore, the free-space loss of the RF signal also changes greatly. At certain combinations of the attitude and look angle to the ground stations, body-fixed antennas must be switched to avoid null antenna gain (Fig. 10). To adapt to these situations, the appropriate downlink rate $(4,64 \mathrm{kbps}, 0.5$, or $1 \mathrm{Mbps}$ ), RF output power (high or low), and type of body-fixed antenna (dipole or cross-dipole) had to be selected in a timely manner to maximize the amount of downloaded mission data. This kind of operation planning is a complicated multidisciplinary engineering challenge. To solve this problem, we developed two types of command planning software that were used to calculate the timing for switching communication modes. The first one used a fast, robust, and relatively simple algorithm, but a limited amount of mission data could be downloaded using this approach. The second one used an optimized algorithm called the graph-theoretic approach (Someya et al. 2017). The communication link margins were calculated to modify the software accordingly such that the appropriate antenna pattern could be estimated while in orbit. While both algorithms worked well, the antenna configurations determined by the graph-theoretic approach allowed approximately $30 \%$ more data to be transmitted than those determined using the simple algorithm.

\section{Flexible standardized bus and its modifications}

Table 7 summarizes the challenges of applying the flexible standardized bus and its modifications in this project as well as the strategies used to address these issues. 


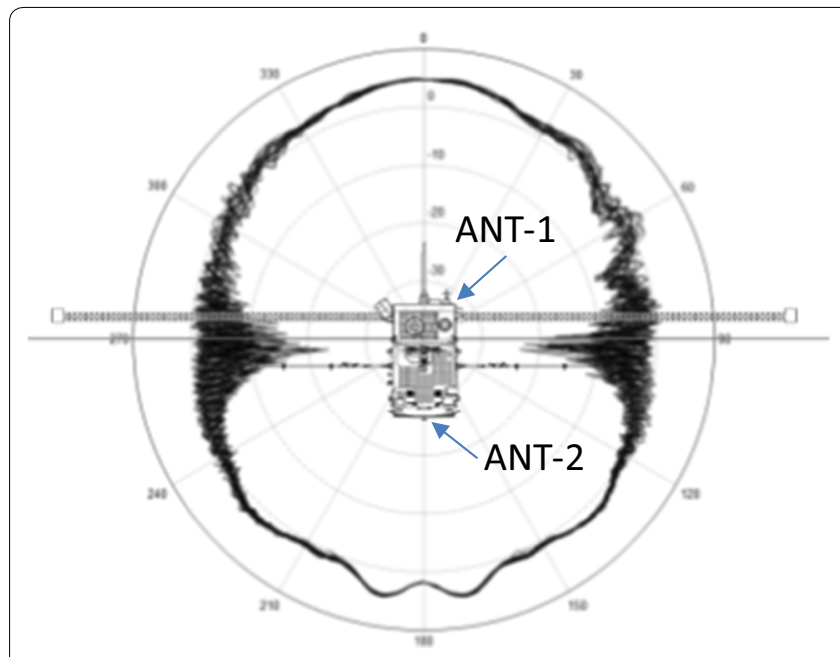

ANT-1, ANT-2 combined antenna pattern (Transmission)

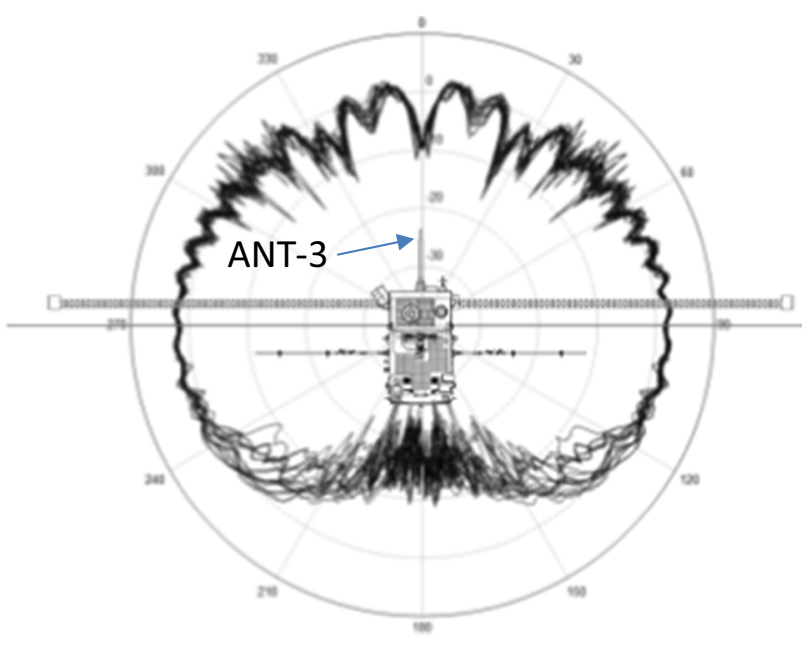

ANT-3 antenna pattern (Transmission)

Fig. 10 Analyzed antenna patterns of the ERG. A dipole antenna called ANT-3 and a cross-dipole antenna called ANT-1 are attached to the mission module, and another cross-dipole antenna called ANT-2 is attached beneath the bus module. Signals to and from ANT-1 and ANT-2 are combined using S-band hybrid coupler

\begin{tabular}{|c|c|}
\hline Challenges & Solutions \\
\hline \multirow{4}{*}{$\begin{array}{l}\text { Taking maximum } \\
\text { advantage of the } \\
\text { flexible standard- } \\
\text { ized bus }\end{array}$} & Flight-proven components and bus system \\
\hline & Reuse of telemetry and command database \\
\hline & Generic spacecraft test and operations software \\
\hline & Minimizing development period and cost \\
\hline \multirow{2}{*}{$\begin{array}{l}\text { Demonstrate the } \\
\text { flexible standard- } \\
\text { ized bus concept }\end{array}$} & $\begin{array}{l}\text { Three-axis stabilization or spin stabilization } \\
\text { selectable }\end{array}$ \\
\hline & Thrusters or no thrusters selectable \\
\hline \multirow{2}{*}{$\begin{array}{l}\text { The ERG mission-spe- } \\
\text { cific modification }\end{array}$} & Modified design of resistance to radiation \\
\hline & Modified design of EMC \\
\hline
\end{tabular}

The ERG satellite is the second satellite in a series of small scientific satellites. Considerable benefits were achieved from the implementation of the small, flexible standardized scientific satellite bus:

- Issues during the development of the satellite system and its components were greatly reduced.

- The satellite telemetry and command design and definitions database could be reused.
- As the mechanical test model (MTM) of the bus module was already tested in the first satellite project, only a test mission module MTM needed to be tested.

- The use of the same bus components reduced the human resources required for the bus subsystems.

- The ground test and operation system, which we call the generic spacecraft test and operations software, was standardized, and the functions, telemetry, and command information of the satellite were loaded from a database to provide standard operation interfaces; thus, this software greatly reduced the effort required to develop the ERG satellite's test and ground system.

The flexible standardized bus provides selectable (or alternative) options and was originally designed to conduct three-axis stabilization or spin stabilization in a satellite. The first satellite to use this small, flexible standardized scientific satellite bus was SPRINT-A, or "HISAKI", an extreme-ultraviolet-range space telescope that was designed to conduct remote observations of planets and launched in 2013. SPRINT-A was a lowEarth-orbit (LEO) satellite with three-axis control and an inertially fixed attitude. However, the ERG satellite is spin-stabilized and has a Sun-pointing attitude and a 


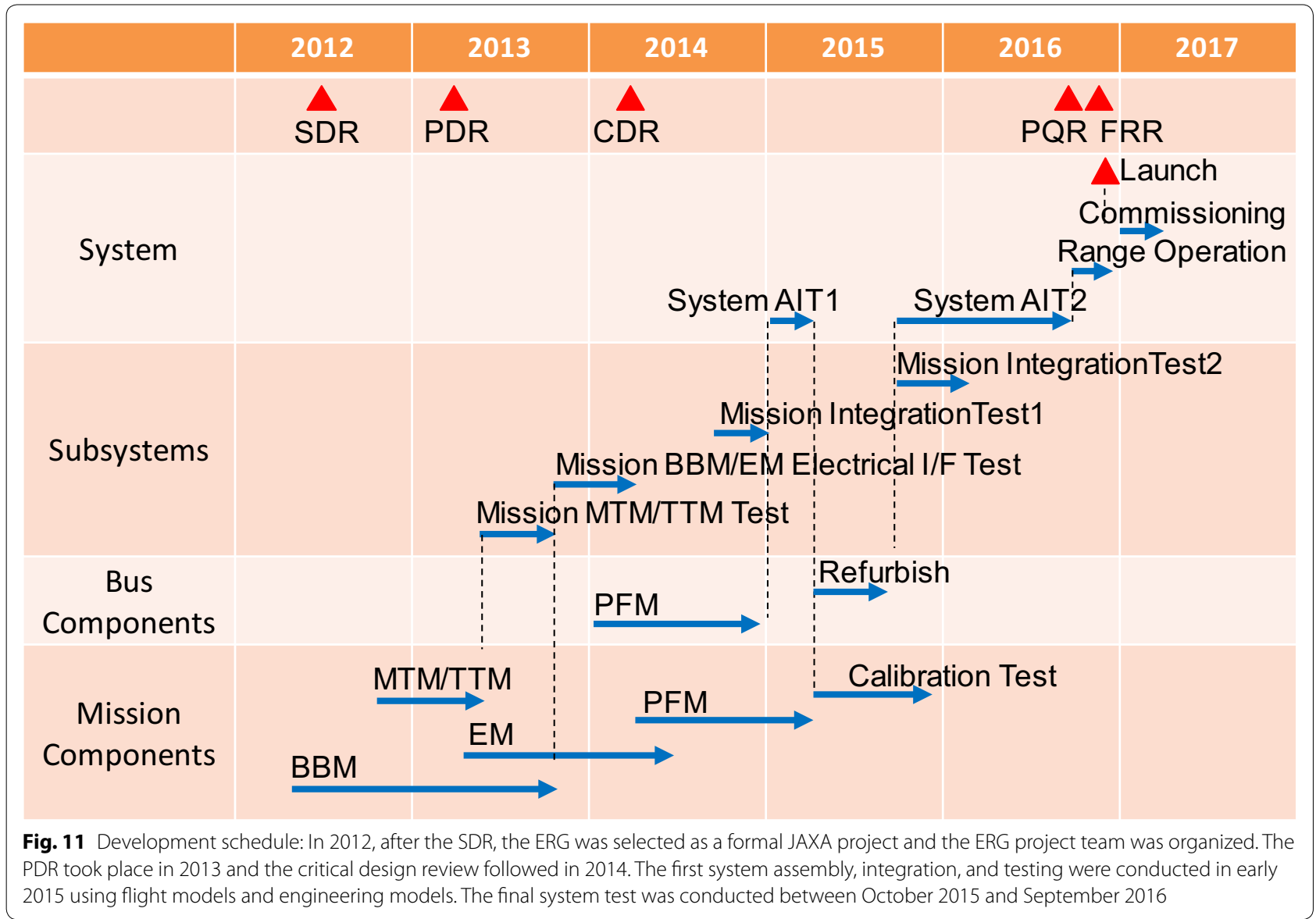

highly elliptical orbit. Thus, while SPRINT-A did not have thrusters, a hydrazine thruster system was adopted for the ERG satellite to provide delta- $\mathrm{V}$ and spin control. Furthermore, radiation environment and EMC requirements (RE02/RE04) of SPRINT-A were not so severe, and the ERG satellite modified its designs as introduced in the former section. By leveraging the advantages of the flexible standardized bus, the ERG satellite system was adequately customized based on the various requirements.

\section{Development and flight operations}

\section{Development of ERG}

Figure 11 shows the project schedule. After the SDR, breadboard models (BBMs) and engineering models (EM) of the mission components were designed and tested. A MTM and a thermal test model (TTM) of the mission module structure were also designed and tested to confirm that they can withstand vibration and thermal environmental conditions. The EM, MTM, and TTM phases for the bus system could be skipped due to the use of a standard bus concept. The first phase of system assembly, integration, and testing (AIT) was conducted in early 2015 using flight models and EM. The final AIT was conducted between October 2015 and September 2016.

\section{Launch phase}

The second Epsilon launch vehicle carrying the ERG satellite was launched successfully at 11:00 UTC on December 20, 2016, from the Uchinoura Space Center. The launch vehicle flew as planned, and the separation of the ERG satellite was confirmed approximately $13 \mathrm{~min}$ and $27 \mathrm{~s}$ after liftoff via a signal received at the Santiago Ground Station in the Republic of Chile at 11:37 UTC. 


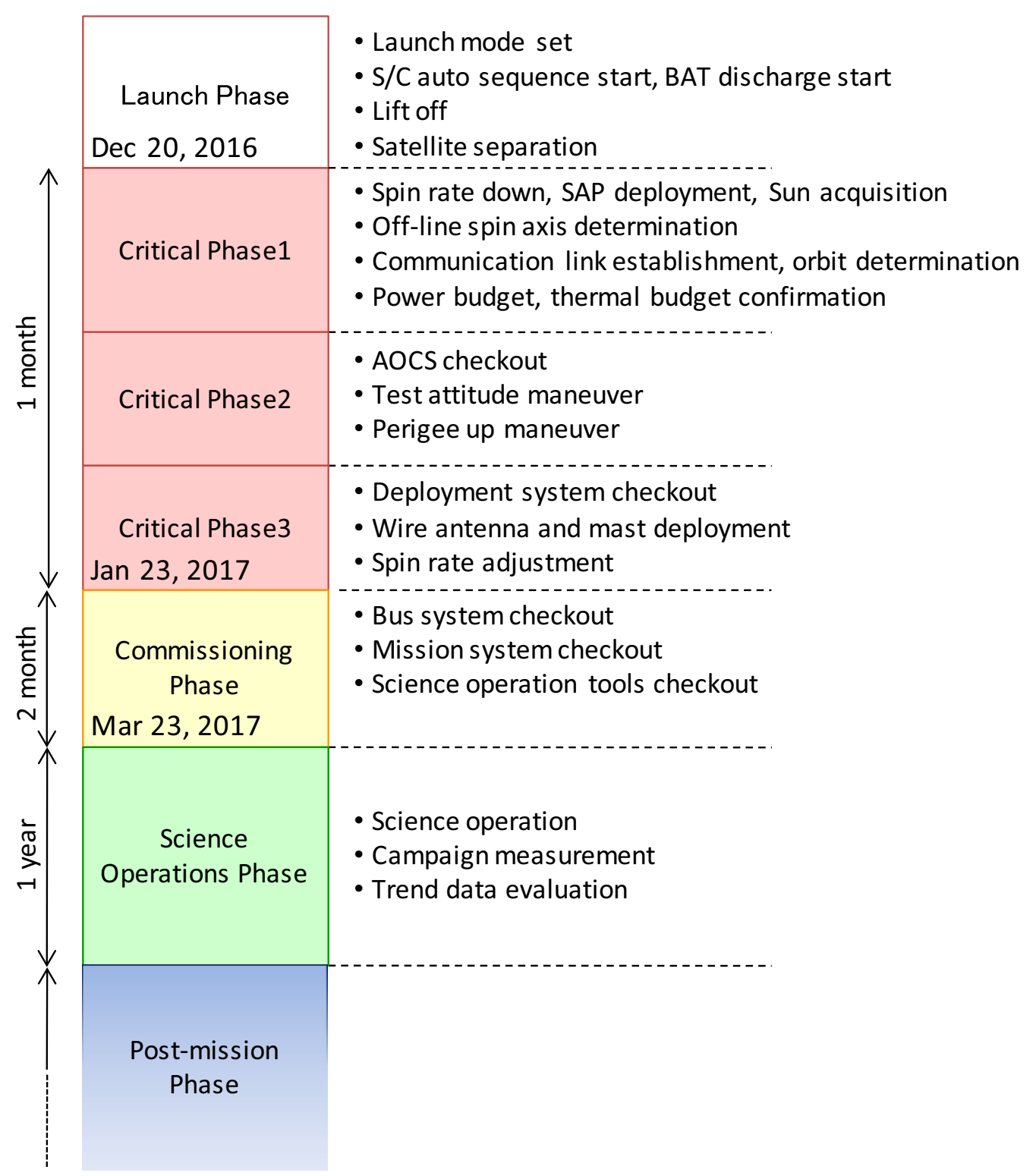

Fig. 12 Operation phase of the ERG project

Figure 12 defines the operation phases in the ERG project, starting with the launch phase; the subsequent phases are described in the following sections.

\section{Critical operation phase}

The critical operation phase lasted about 1 month as was divided into three phases. In the first critical phase, the ERG satellite completed a spin-down and executed active nutation control, SAP deployment, and Sun-position acquisition (Fig. 13). The first apogee pass was over the southern hemisphere; the pass over the Santiago Ground Station lasted nearly $9 \mathrm{~h}$ (Fig. 14). The second apogee pass was over the ground stations in Japan and was also nearly $9 \mathrm{~h}$; this time was used to check the satellite status. During this period, the operation team confirmed that a communication link was established, checked the power 


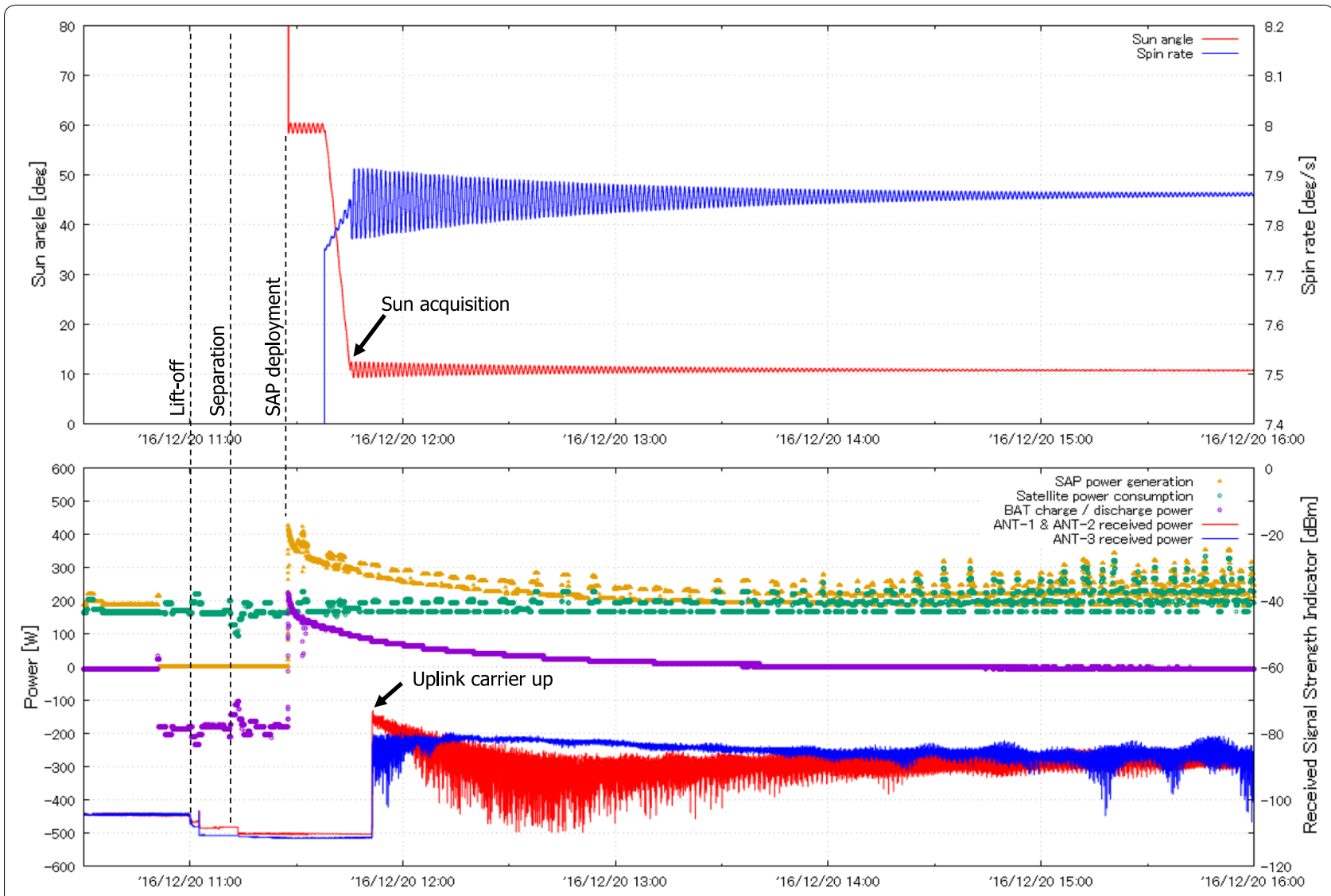

Fig. 13 Flight data from the attitude, power, and communication subsystems during the launch and early orbit phases

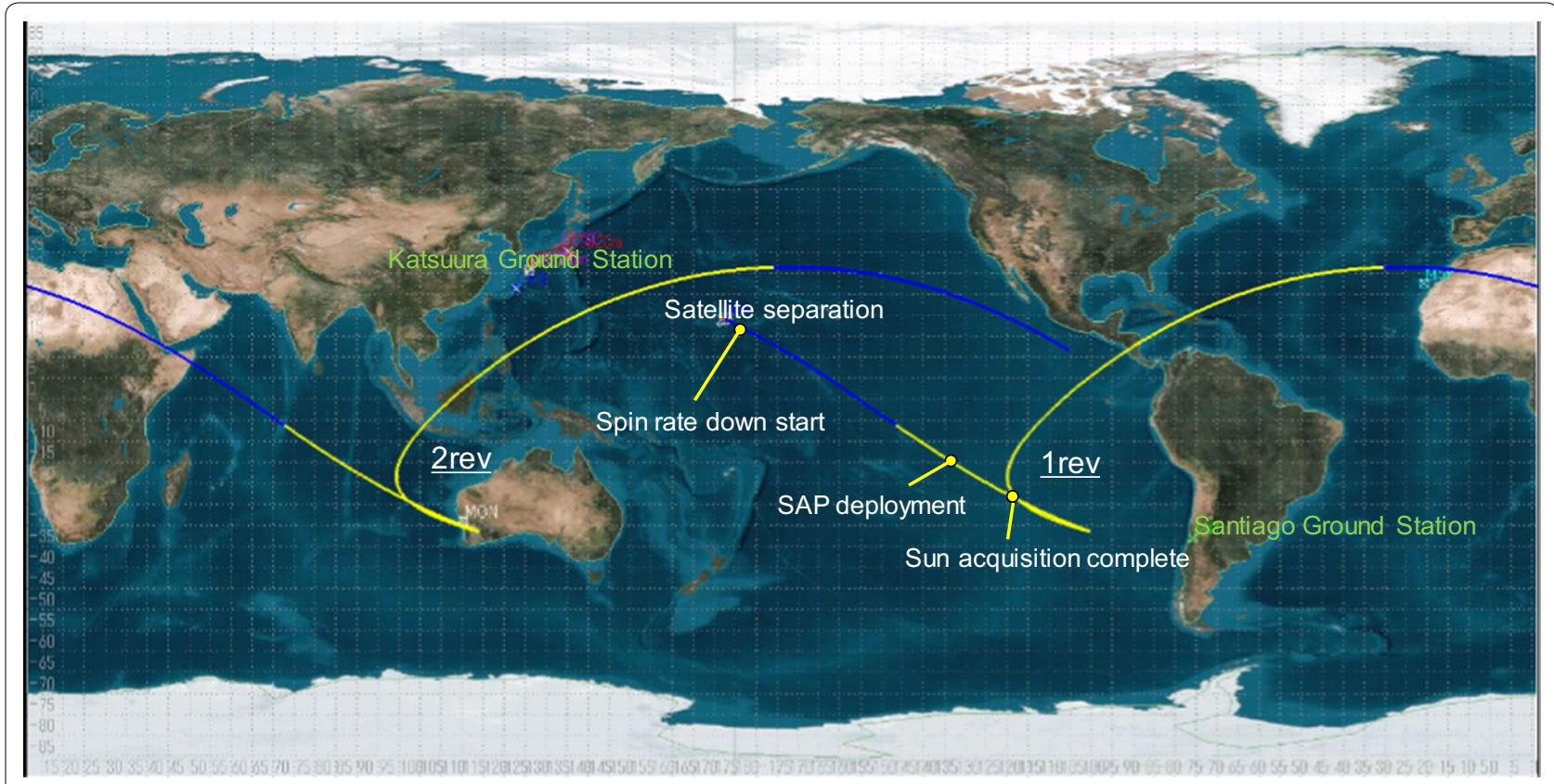

Fig. 14 Ground trace of the ERG for first two revolutions after separation from the launch vehicle. The color of the trace line is blue when the satellite is in eclipse and yellow when the satellite is in sunlight 

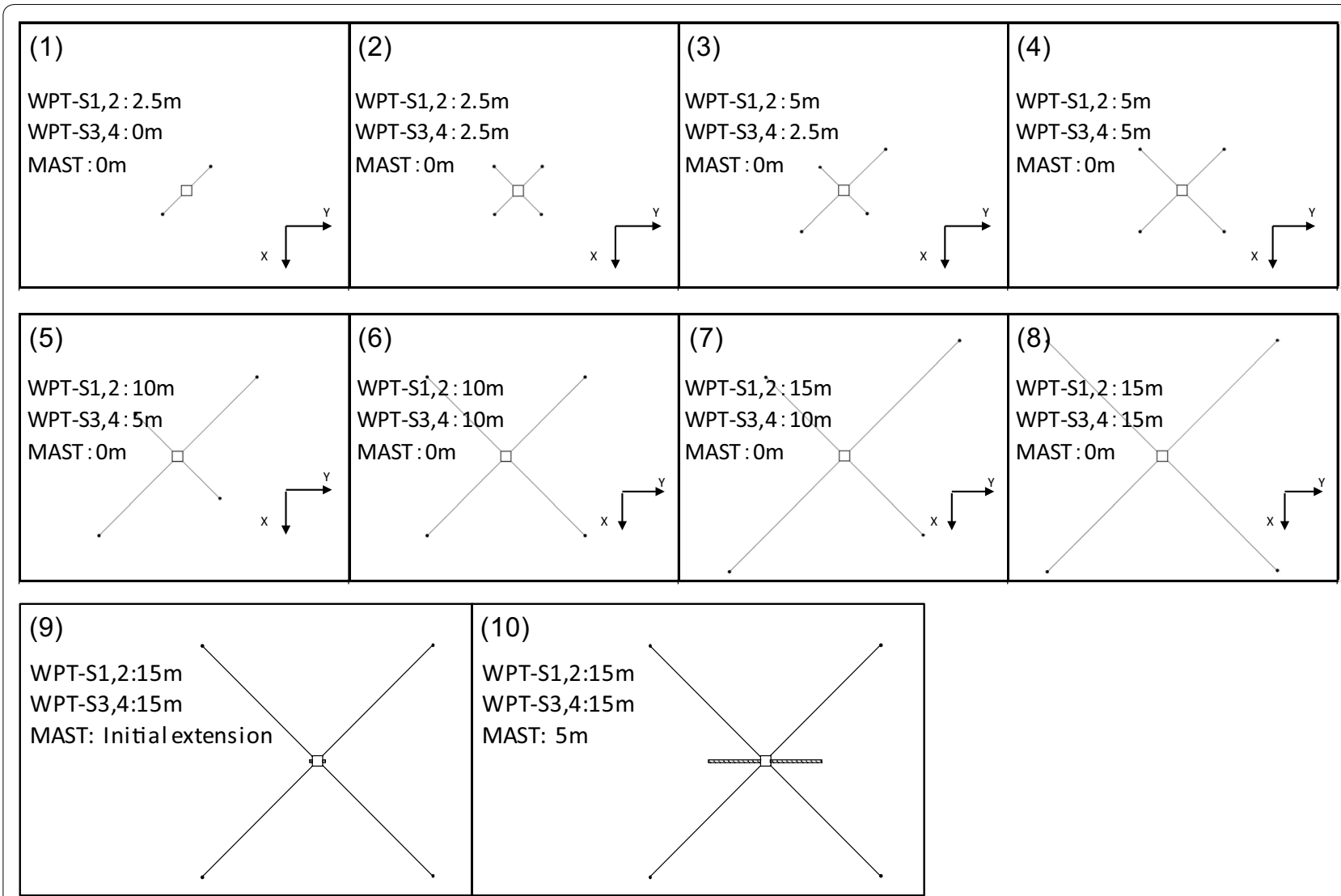

Fig. 15 Deployment sequence for the wire probe antennas and masts

and thermal budget, and characterized the orbit. This first part of the critical operation phase spanned around 3 days.

In the second critical phase, perigee-up delta- $\mathrm{V}$ maneuvers were required because the initial perigee altitude of $214 \mathrm{~km}$ was so low that the apogee altitude would diminish rapidly and the $\mathrm{AO}$ around the perigee would erode surface materials. Before these maneuvers were carried out, the AOCS functions were checked step by step, including the execution of test attitude maneuvers and a test delta- $\mathrm{V}$ maneuver. The actual delta- $\mathrm{V}$ maneuvers were conducted twice to reduce the risk of a maneuver control error; as a result, the perigee altitude was increased to $440 \mathrm{~km}$ as intended.

The $15-\mathrm{m}$ wire probe antennas and the 5-m extendable masts were deployed in the third critical phase (Fig. 15). Because these structures are flexible, the deployment operations were again conducted step by step while paying close attention to the attitude of the satellite (Fig. 16). Finally, the spin rate of the satellite was adjusted to $7.5 \mathrm{rpm}$ using thrusters.

\section{Commissioning phase}

In commissioning phase, the subsystem functions were tested and a performance checkout was conducted prior to the initial start-up of the mission instruments including the high-voltage-power supply. In order to avoid electrical discharges due to outgassing under insufficient vacuum conditions, the start-up of the high-voltagepower supply was delayed by at least 1 month. After all mission components were started and the initial mission data were verified, operation training and planning were conducted. The verification tools were checked, and the 

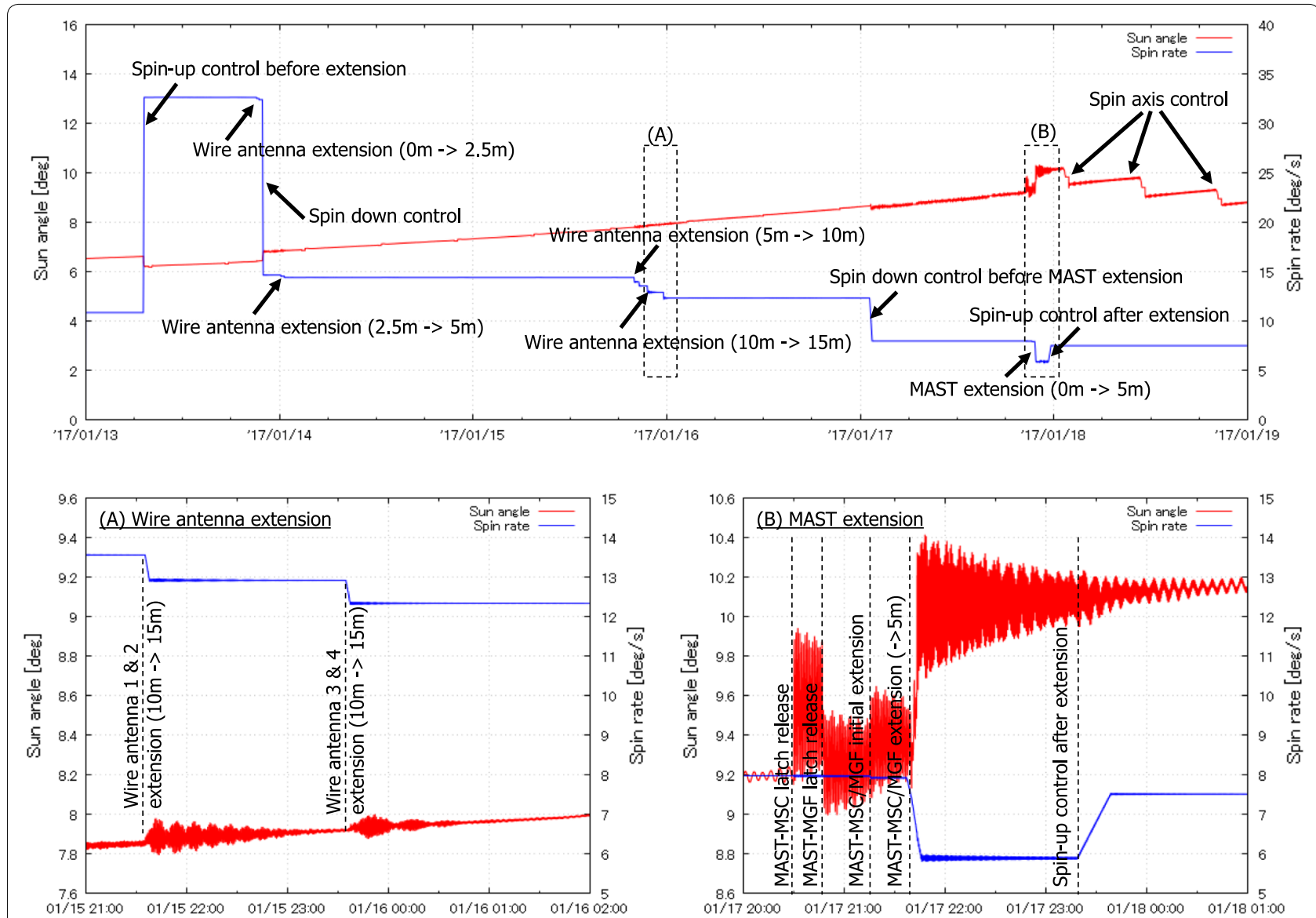

Fig. 16 Flight data regarding the Sun angle (angle between the spin vector and Sun vector) and the spin rate in the deployment of the wire probe antennas and masts. $\mathbf{a}$ and $\mathbf{b}$ The Sun angle, and therefore the nutation angle of the satellite, is higher during deployment operations and slowly returns to a lower value thereafter

satellite parameters were modified to prepare for the science operation phase.

\section{Science operation phase}

After a successful commissioning phase, the ERG project entered the science operation phase on March 24, 2017. Figure 17 shows an image of the operation of the ERG satellite in its highly elliptical orbit. The ERG is mainly operated using JAXA's ground stations in Uchinoura (34 and $20 \mathrm{~m}$ diameter), Katsuura (20 m diameter), and Okinawa (18 $\mathrm{m}$ diameter) for high-speed communication around the apogee. JAXA's 10-m-diameter ground stations for
LEO communication are also utilized for operations around the perigee. Scientific data are recorded continuously by the mission data recorder, and an enormous amount of mission data is recorded when space storms or other space events occur. Thus, most of the longpass windows around the apogee above Japan are used to downlink the mission data at a high speed ( 0.5 or 1 Mbps) via S-band communication. On the other hand, the pass windows around the perigee are used for lowspeed (4 or $64 \mathrm{kbps}$ ) operations in the S-band. Because the altitude is so low at the perigee, non-negligible orbit perturbations occur due to the air drag. Satellite ranging 


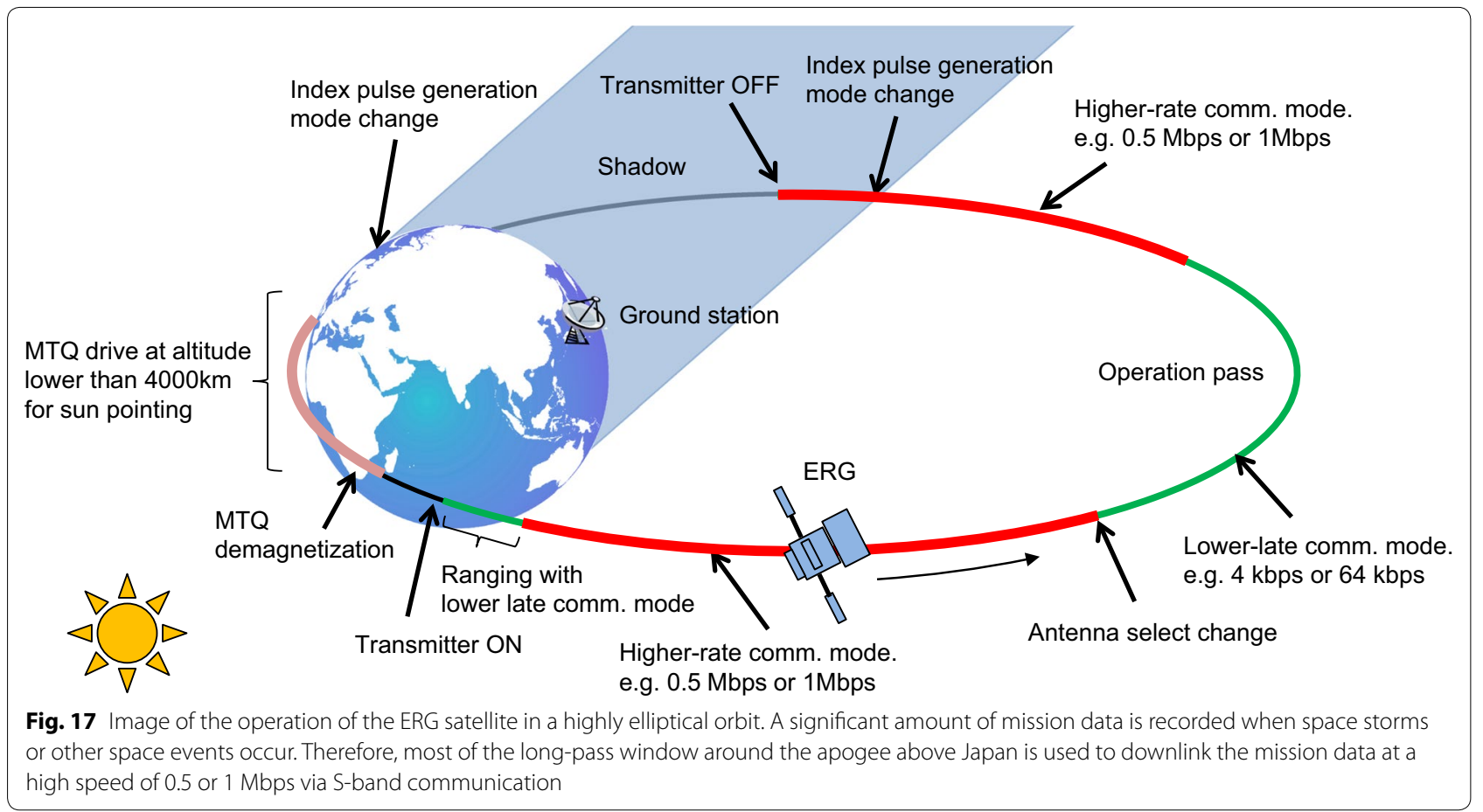

for orbit determination must be conducted frequently (at least one arc around the perigee per day along the orbit of three revolutions per day).

In order to synchronize the scientific data collected by multiple instruments, an index pulse (IP) was distributed to each instrument by the AOCP. An IP is normally generated from a Sun detection pulse generated by the SSAS in each spin, but when the satellite is in the shadow of the Earth, the IP generation mode must be changed to automated IP mode. However, the duration of the eclipse changes as the orbit is perturbed. When the apogee is in the Earth's shadow, the eclipse lasts around $2 \mathrm{~h}$, and the scientific observation mode is shifted to the degenerate mode in which several instruments are switched to standby mode to save electrical power.

Figure 18 shows the flight data regarding the Sun angle (the angle between the spin vector and the Sun vector), the MTQ drive duty, the GAS measurements, and the altitude of the satellite. The spin vector is controlled moderately by the MTQs at every perigee such that nutation motion is not induced. Note that after each MTQ operation, MTQ demagnetization comprising a sequence of fast and attenuating positive and negative alternate drives is conducted to minimize the magnetization effect on the satellite.

The regular science operation phase has been ongoing since March 24, 2017, after the initial critical and checkout phases were successfully completed. Thanks to the comprehensive management to satisfy any requirements, such as EMC, all of the mission instruments are currently functioning as intended, and no degradation has been observed over a year of flight operations. Figure 19 summarizes all of the data collected from the mission sensors on December 20, 2017: (a)-(d) show the temporal variations in the plasma wave power spectra (referred to as the dynamic power spectra), (e)-(h) show the temporal variations in the electron energy spectra (referred to as the dynamic energy spectra); (i)-(j) show the dynamic energy spectra of ions; and (k) shows the DC magnetic field recorded in the MGF. The white blanks in panels (a)-(j) represent periods in which no data or insufficient data were collected or when the satellite was not in observation mode. For example, during the long blanks shown in the ion measurements in (i) and (j), the ion 


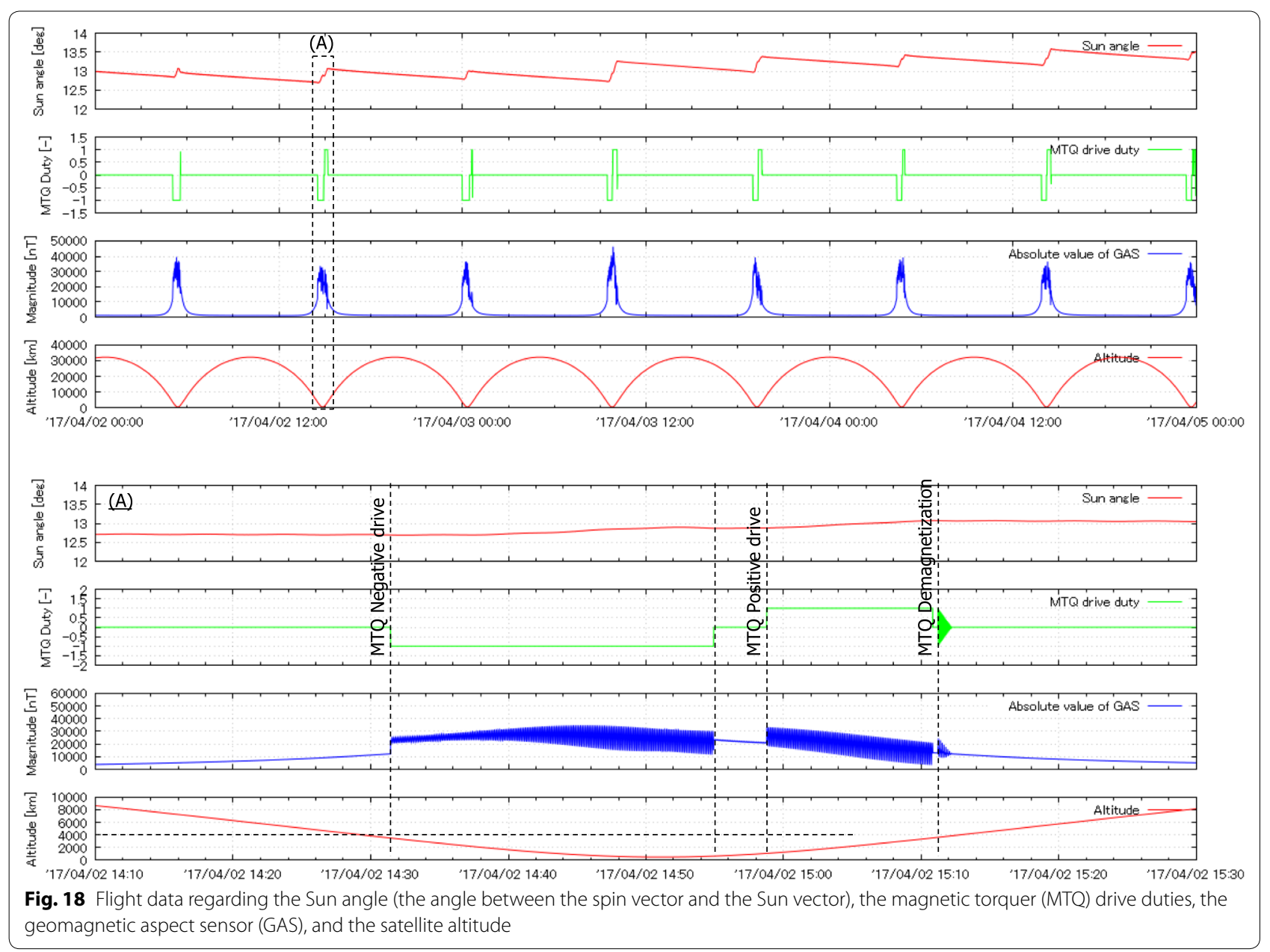

analyzers were in the time-of-flight (TOF) mode to collect high-resolution ion composition measurements. Since the satellite flies in various regions of geospace during each orbital revolution, these dynamic power spectra and dynamic energy spectra indicate the spatial structure of geospace, including the radiation belts. The detailed descriptions and initial observations of each of the mission experiments can be found in other papers: Kasahara et al. (2018a), Ozaki et al. (2018), Kumamoto et al. (2018), Kasaba et al. (2017) and Matsuda et al. (2018) reported on the PWE, Higashio et al. (in review) reported on the XEP, Matsuoka et al. (2018) reported on the MGF, and Mitani et al. (2018) reported on the HEP; moreover, the data from the MEP-e, LEP-e, MEP-i, and LEP-i have been reported and evaluated by Kasahara et al. (2018b), Kazama et al. (2017), Yokota et al. (2018) and Asamura et al. (2018), respectively.

\section{Summary}

The ERG satellite, nicknamed "Arase," is the second satellite in a series of small scientific satellites developed by the ISAS of the JAXA. It was launched on December 20, 2016, by the Epsilon launch vehicle. In this article, we introduced and summarized the four major challenges and mitigation strategies in this project: (1) extremely harsh conditions in orbit and the requirements for EMC, (2) the need to stabilize the spin attitude stabilization and to minimize the libration of the flexible structures, 

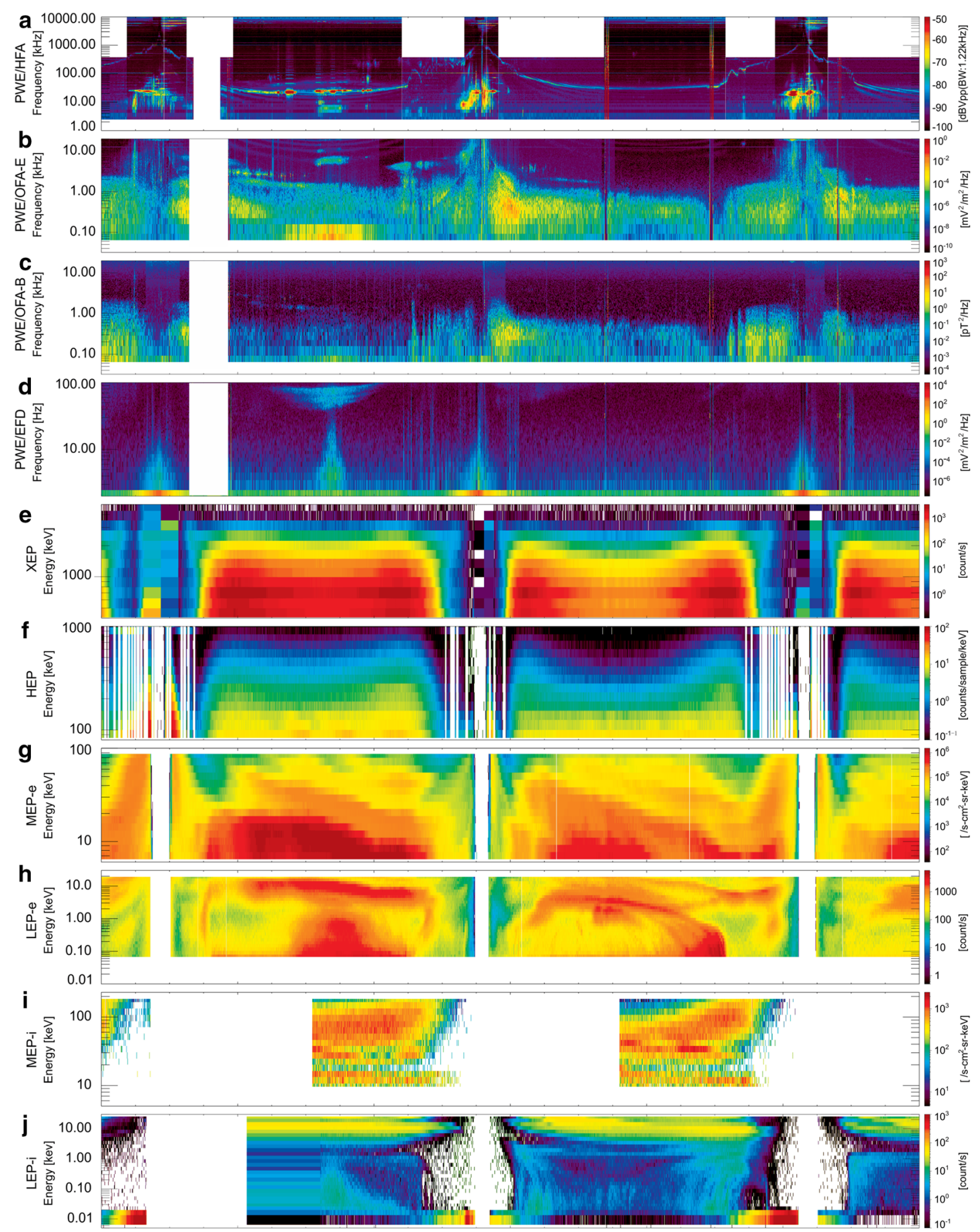

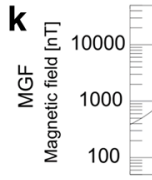

$\begin{array}{llllllll}\text { Lm } & 4.2 & 5.1 & 5.5 & 4.1 & 6.6 & 2.7 & \\ \text { MLT } & 16.3 & 12.7 & 15.6 & 10.8 & 14.7 & 18.5 & 13.1 \\ \text { MLAT } & 1.1 & 14.6 & -5.1 & 35.6 & 16.2 & -23.1 & 18.0 \\ \text { hhmm } & 0000 & 0400 & 0800 & 1200 & 1600 & 2000\end{array}$

Dec. 20, 2017 


\section{(See figure on previous page.)}

Fig. 19 Summary of all mission data recorded on December 20, 2017. The top four panels show the temporal variation in the plasma wave power spectra: a the electric field power spectra at $10 \mathrm{kHz}-10 \mathrm{MHz}$ as recorded by the PWE high-frequency analyzer (HFA), $\mathbf{b}$ the electric field and $\mathbf{c}$ the magnetic field power spectra at $10 \mathrm{~Hz}-20 \mathrm{kHz}$ recorded by the PWE onboard frequency analyzer, and $\mathbf{d}$ the electric field power spectra at DC-200 Hz recorded by the electric field detector. The next six panels show the temporal variation in the particle energy spectra of e $400 \mathrm{keV}-$ $20 \mathrm{MeV}$ electrons as recorded by the XEP, $\mathbf{f} 70 \mathrm{keV}-1 \mathrm{MeV}$ particles as recorded in the high-energy particle experiments, $\mathbf{g} 10-80 \mathrm{keV}$ electrons as recorded by the MEP-e, $\mathbf{h} 19 \mathrm{eV}-19 \mathrm{keV}$ electrons as recorded by the LEP-e, i 10-180 keV/q ions as recorded by the MEP-i, and j $10 \mathrm{eV} / \mathrm{q}-25 \mathrm{keV} / \mathrm{q}$ ions as recorded by the LEP-i. The bottom panel k shows the DC magnetic field recorded in the MGF experiments. The white blanks in panels $\mathbf{a}-\mathbf{j}$ represent no or insufficient data or observations or observations made in a mode other than the observation mode. For example, during the long blanks shown in the ion measurements in (i) and ( $\mathbf{j}$ ), the ion analyzers were in TOF mode to conduct high-resolution ion composition measurements

(3) maintaining an appropriate balance between the mission requirements and the limited resources of this small satellite, and (4) the modification and implementation of a flexible standardized bus. These challenges were addressed through the design, development, and operation phases. The results have been successful thus far: the satellite is now in good condition and is consistently obtaining excellent scientific data in orbit. A detailed report on each of the ERG scientific instruments will be published as a series of articles in this issue.

\begin{abstract}
Abbreviations
JAXA: Japan Aerospace Exploration Agency; ISAS: Institute of Space and Astronautical Science; ERG: exploration of energization and radiation in geospace; SDR: system definition review; PDR: preliminary design review; CDR: critical design review; SAP: solar-array panel; PPE: plasma and particle experiment; MGF: magnetic field experiment; PWE: plasma wave experiment; S-WPIA: software-type wave-particle interaction analyzer; SMS: satellite management subsystem; SMU: satellite management unit; DR: data recorder; TCIM: telemetry and command interface module; AOCP: attitude and orbit control processor; PCU: power control unit; HCE: heater control electronics; MDP-E: mission data processor electronics; SWR: spaceWire network router; ACIM: attitude control interface module; RCS: reaction control subsystem; SSAS: spintype sun aspect sensor; GAS: geomagnetic aspect sensor; SSC: small star scanner; EMC: electromagnetic compatibility; AO: atomic oxygen; SOl: silicon on insulator; MDP/MDR: mission data processor/data recorder; BBM: breadboard model; EM: engineering model; MTM: mechanical test model; TTM: thermal test model; AIT: assembly, integration, and testing; AOS: acquisition of signal; LOS: loss of signal; IP: index pulse; MTQ: magnetic torquer; TOF: time-of-flight.
\end{abstract}

\section{Authors' contributions}

$\mathrm{SF}, \mathrm{KN}, \mathrm{KM}, \mathrm{MM}, \mathrm{EO}, \mathrm{YK}$ are ERG system engineers and conducted the satellite system design, development, and operations. YS, HO, SS, SS, ES, YM, HT, AK, $J N, Y M, T S$, and ST are ERG subsystem engineers and conducted the design, development, and operations of the satellite subsystems. KA and TT are ERG mission system and science instrument managers and conducted the satellite mission system design, development, and operations. YN and IS are ERG project managers and conducted the project management and satellite system design, development, and operations. All authors read and approved the final manuscript.

\section{Author details}

${ }^{1}$ Institute of Space and Astronautical Science, Japan Aerospace Exploration Agency, JAXA, 3-1-1 Yoshinodai, Chuo-ku, Sagamihara, Kanagawa 252-5210, Japan. ${ }^{2}$ Research and Development Directorate, Japan Aerospace Exploration Agency, JAXA, 2-1-1, Sengen, Tsukuba, Ibaraki 305-8505, Japan.

\section{Acknowledgements}

The ERG team acknowledges the effort of Dr. Y. Miyoshi and ERG science center at Nagoya University and all member of the ERG science team. We also express our thanks to Messrs T. Ohshima, T. Okahashi, T. Yoshino, and Mses. M. Bunazawa, and E. Ujiie (NEC Corporation) for fabrication and operation of the satellite system, M. Koyama, and K. Fukuzawa (Mitsubishi Heavy Industries Ltd.) for fabrication and operation of the mission system. The measures to satisfy the EMC requirements were conducted by the ERG-EMC board members, Drs. H. Kojima, A. Matsuoka, R. Nomura, M. Teramoto, Mita, S. Nakazawa, M. Murashima. The authors wish to express their thanks to colleagues of the Arase project team members and ISAS staffs for their support during the development and operation of the ERG.

\section{Competing interests}

The authors declare that they have no competing interests.

\section{Availability of data and materials}

The ERG (Arase) science data will be available in the data server at the ERG Science Center operated by ISAS/JAXA and ISEE/Nagoya University (http://ergsC isee.nagoya-u.ac.jp/). Satellite system data and materials are available from the corresponding author upon reasonable request.

\section{Consent for publication}

Not applicable.

\section{Ethics approval and consent to participate}

Not applicable.

\section{Funding}

The ERG (Arase) project is funded by ISAS/JAXA.

\section{Publisher's Note}

Springer Nature remains neutral with regard to jurisdictional claims in published maps and institutional affiliations.

Received: 10 October 2017 Accepted: 16 May 2018

Published online: 26 June 2018

\section{References}

Asamura K, Kazama Y, Yokota S, Kasahara S, Miyoshi Y (2018) Low-energy particle experiments-ion mass analyzer (LEPi) onboard the ERG (Arase) satellite. Earth Planets Space. https://doi.org/10.1186/s40623-018-0846-0

Ebihara Y, Miyoshi Y (2011) Dynamic inner magnetosphere: a tutorial and recent advances. In: Liu W, Fujimoto M (eds) The dynamic magnetosphere, vol 3. IAGA spec. sopron book ser. Springer, Dordrecht, pp 145-187. https://doi.org/10.1007/978-94-007-0501-2_9

Kasaba Y, Ishisaka K, Kasahara Y, Imachi T, Yagitani S, Kojima H, Matsuda S, Shoji M, Kurita S, Hori T, Shinbori A, Teramoto M, Miyoshi Y, Nakagawa T, Takahashi N, Nishimura Y, Matsuoka A, Kumamoto A, Tsuchiya F, Nomura R (2017) Wire probe antenna (WPT) and electric field detector (EFD) of plasma wave experiment (PWE) aboard the Arase satellite: specifications and initial evaluation results. Earth Planets Space. https://doi.org/10.1186/ s40623-017-0760-x 
Kasahara Y, Kasaba Y, Kojima H, Yagitani S, Ishisaka K, Kumamoto A, Tsuchiya F, Ozaki M, Matsuda S, Imachi T, Miyoshi Y, Hikishima M, Katoh Y, Ota M, Shoji M, Matsuoka A, Shinohara I (2018a) The plasma wave experiment (PWE) on board the Arase (ERG) satellite. Earth Planets Space. https://doi. org/10.1186/s40623-018-0842-4

Kasahara S, Yokota S, Mitani T, Asamura K, Hirahara M, Shibano Y, Takshima T (2018b) Medium-energy particle experiments-electron analyzer (MEP-e) for the exploration of energization and radiation in geospace (ERG) mission. Earth Planets Space. https://doi.org/10.1186/s40623-018-0847-z

Kazama Y, Wang BJ, Wang SY, Ho PTP, Tam SWY, Chang TF, Chiang CY, Asamura K (2017) Low-energy particle experiments-electron analyzer (LEPe) onboard the Arase spacecraft. Earth Planets Space. https://doi. org/10.1186/s40623-017-0748-6

Kumamoto A, Tsuchiya F, Kasahara Y, Kasaba Y, Kojima H, Yagitani S, Ishisaka K, Imachi T, Ozaki M, Matsuda S, Shoji M, Matsuoka A, Katoh Y, Miyoshi Y, Obara T (2018) High frequency analyzer (HFA) of plasma wave experiment (PWE) onboard the Arase spacecraft. Earth Planets Space. https:// doi.org/10.1186/s40623-018-0854-0

Matsuda S, Kasahara Y, Kojima H, Kasaba Y, Yagitani S, Ozaki M, Imachi T, Ishisaka K, Kumamoto A, Tsuchiya F, Ota M, Kurita S, Miyoshi Y, Hikishima M, Matsuoka A, Shinohara I (2018) Onboard software of plasma wave experiment aboard Arase: instrument management and signal processing of wave form capture/onboard frequency analyzer. Earth Planets Space. https://doi.org/10.1186/s40623-018-0838-0

Matsuoka A, Teramoto M, Nomura R, Nose M, Fujimoto A, Tanaka Y, Shinohara M, Nagatsuma T, Shiokawa K, Obana Y, Miyoshi Y, Mita M, Takashima T, Shinohara I (2018) The Arase (ERG) magnetic field investigation. Earth Planets Space. https://doi.org/10.1186/s40623-018-0800-1

Mitani T, Takashima T, Kasahara S, Miyake W, Hirahara M (2018) High-energy electron experiments (HEP) aboard the ERG spacecraft. Earth Planets Space. https://doi.org/10.1186/s40623-018-0853-1
Miyoshi Y et al (2012) The energization and radiation in geospace (ERG) project. In: Baker N (ed) Dynamics of the Earth's radiation belts and inner magnetosphere. Geophysical monograph series, vol 199. Wiley, New York. https://doi.org/10.1029/2012GM001304

Nakaya Ket al (2012) Development of flexible standard bus for ISAS/ JAXA small scientific satellite series. Trans JSASS Aerosp Technol Jpn 10(ists28):Tf_5-Tf_9. https://doi.org/10.2322/tastj.10.Tf_5

Ozaki M, Yagitani S, Kojima H, Kasahara Y, Kasaba Y, Matsuoka A, Sasaki T, Yumoto T (2018) Magnetic search coil (MSC) of plasma wave experiment (PWE) aboard the Arase (ERG) satellite. Earth Planets Space. https://doi. org/10.1186/s40623-018-0837-1

Shibano $Y$ et al (2015) Thermal performance degradation of spacecraft radiator by outgassing of adhesives in space environment. In: The 13th international symposium on materials in the space environment, Pau

Soken HE et al (2017) Spin parameters and nonlinear Kalman filtering for spinning spacecraft attitude estimation, 2017 Space flight mechanics meeting, San Antonio, AAS, pp 17-249

Someya K et al (2017) A graph-theoretic approach to optimal planning of satellite downlink. In: 31st international symposium on space technology and science (ISTS), Matsuyama, 2017-n-03

Takashima T, Ogawa E, Asamura K, Hikishima M (2018) Design of mission network system with SpaceWire for scientific payloads onboard the ARASE spacecraft. Earth Planets Space. https://doi.org/10.1186/s4062 3-018-0839-Z

van Allen JA, Frank LA (1959) Radiation around the Earth to a radial distance of 107,400 km. Nature 183(4659):430-434

Yokota S, Kasahara S, Mitani T, Asamura K, Hirahara M, Takashima T, Yamamoto K, Shibano Y (2018) Medium-energy particle experiments-ion mass analyzer (MEP-i) onboard ERG (Arase). Earth Planets Space. https://doi. org/10.1186/s40623-017-0754-8

\section{Submit your manuscript to a SpringerOpen ${ }^{\circ}$ journal and benefit from:}

- Convenient online submission

- Rigorous peer review

- Open access: articles freely available online

- High visibility within the field

- Retaining the copyright to your article

Submit your next manuscript at $\boldsymbol{\nabla}$ springeropen.com 